This item was submitted to Loughborough's Research Repository by the author.

Items in Figshare are protected by copyright, with all rights reserved, unless otherwise indicated.

\title{
Sensitivity analysis of proposed natural ventilation IEQ designs for archetypal open-plan office layouts in a temperate climate
}

\section{PLEASE CITE THE PUBLISHED VERSION}

https://doi.org/10.1080/17512549.2020.1813197

\section{PUBLISHER}

Taylor \& Francis

\section{VERSION}

AM (Accepted Manuscript)

\section{PUBLISHER STATEMENT}

This is an Accepted Manuscript of an article published by Taylor \& Francis in Advances in Building Energy Research on 2 Sept 2020, available online: https://doi.org/10.1080/17512549.2020.1813197

\section{LICENCE}

CC BY-NC-ND 4.0

\section{REPOSITORY RECORD}

Corbett, Thomas, Eftychia Spentzou, and Mahroo Eftekhari. 2020. "Sensitivity Analysis of Proposed Natural Ventilation IEQ Designs for Archetypal Open-plan Office Layouts in a Temperate Climate". Loughborough University. https://hdl.handle.net/2134/12815606.v1. 
Sensitivity analysis of proposed natural ventilation IEQ designs for archetypal open-plan office layouts in a temperate climate

\author{
Thomas Corbett $^{1 *}$, Eftychia Spentzou ${ }^{2}$, Mahroo Eftekhari $^{2}$ \\ ${ }^{1}$ School of Architecture and the Built Environment, University of Lincoln, LN6 7TS, \\ Lincoln, UK \\ ${ }^{2}$ School of Architecture, Building and Civil Engineering, Loughborough University, \\ LE11 3TU, Loughborough, UK. \\ *Corresponding author Email: tcorbett@lincoln.ac.uk
}




\title{
Sensitivity analysis of proposed natural ventilation IEQ designs for archetypal open-plan office layouts in a temperate climate
}

\begin{abstract}
:
Designing naturally ventilated deep, open-plan offices could improve occupants' thermal comfort and productivity and ensure energy reductions; however, this can be challenging when relying on façade only openings. This research examines the ventilation performance sensitivity of atria, innovative façade openings and interior layouts of open-plan offices, in order to identify optimal typologies. Different building typologies are developed through a combination of various atria designs and configurations, with the effective use of highaspect-ratio (HAR) openings with a similar dimension to that of the floor-to-ceiling height, in either a mid-level vertical (MLV) or high-level horizontal (HLH) orientation. Steady-state computational fluid dynamics (CFD) simulations are performed to predict internal air flow and temperature distribution in a moderate climate and water-bath modelling (WBM) experiments to validate the computational models. Results showed that MLV provide superior cooling potential (up to $2.5^{\circ} \mathrm{C}$ reductions) and higher ventilations rates; despite, increasing thermal gradients. Unobstructed atria with a horizontal profile similar to that of the building footprint also performed well. Overall, façade opening design was shown to be the most influential design parameter. This research has presented guidance based on reliable results to better equip building designers and architects in the design of successful naturally ventilated deep, open-plan offices.
\end{abstract}

Keywords: Buoyancy driven ventilation, Building design, Computational Fluid Dynamics, Internal Environmental Quality, Natural Ventilation, Thermal Comfort, Water-bath Modelling.

Abbreviations: CFD - Computational Fluid Dynamics, HAR - High Aspect Ratio, HLH - High-level horizontal, IEQ - Internal Environmental Quality, MLV - Mid-level vertical and WBM - Water-bath modelling

\section{Introduction:}

Studies have shown that indoor air quality in office environments can impact occupant wellbeing and job performance. Modern offices are designed to be deep and open-plan in order to maximise productivity, accommodating many occupants and equipment. Natural ventilation can offer healthy indoor conditions, 
occupant wellbeing and thermal comfort and contribute to energy reductions as opposed to mechanical ventilation strategies. In urban environments, utilisation of natural ventilation strategies can be problematic due to high density resulting in lower ventilation rates through the typically single-sided ventilation designs (Spentzou et al, 2018). Atrium designs combined with façade openings could potentially ensure adequate ventilation rates even during buoyancy driven flows (Moosavi, et al 2016). The research reported here aims to explore how atrium designs combined with various openings can impact on the natural ventilation performance of a space.

In naturally ventilated spaces, thermal discomfort in the form of the perceived occurrence of overheating has been reported when internal temperatures exceed the ambient temperature by $4^{\circ} \mathrm{C}$; thus, why this value is often cited as an overheating threshold (BSI, 2007). In many buoyancy-driven, naturally ventilated spaces, thermal stratification commonly leads to discomfort, as a temperature gradient is often created across the body, leading to a noticeable change in temperature and potentially localised air velocities (WGBC, 2016). In order to maximise comfort, temperature gradients (from ankle to standing head height) should be minimised and be below $2^{\circ} \mathrm{C}$ to achieve the highest and most stringent thermal comfort Category I, below $3^{\circ} \mathrm{C}$ for II and below $4^{\circ} \mathrm{C}$ for III (ISO 7730, 2005). These categories illustrate the quality of the thermal environment in terms of expectations and the spaces in which they should be used, with I being high level (sick, very young and elderly), II being normal level (new builds, aiming for less than $10 \%$ dissatisfied occupants) and III being acceptable levels (existing buildings, aiming for less than 15\% dissatisfied occupants) (ISO 7730, 2005). Although the thermal environment can be enhanced through the provision of higher ventilation rates, opening geometries and configurations influence the supply airflow into the space (Moosavi, 2016; Aldawoud, 2016), it can also pose discomfort by creating downdraughts of cooler and faster moving air. Most standards recommend a ventilation rate of around 10.5 1/s pp in order to meet fresh air requirements (CIBSE AM10, 2014 and ANSI/ASHRAE Standard 62.1, 2013); however, previous studies have shown that higher ventilation rates of $20 \mathrm{l} / \mathrm{s} \mathrm{pp}$, can enhance an occupants' perception of IEQ, thermal comfort and productivity (Wargocki et al, 2002; and Chenari et al, 2016).

Building elements, form and the geometry of ventilation openings are all major factors in harnessing the natural driving forces, particularly buoyancy-driven flows, which are required to entrain air into, around and out of a space (Kleiven, 2003 and Moosavi, et al 2016). Internal and external air temperature differentials assist buoyancy-driven flows by generating pressure differences at façade openings. Atria can assist buoyancy-driven 
ventilation, through the implementation of good design parameters regarding opening (size, location, number, state), material (thermal mass), fenestration (height, material, shading device) and the atrium itself (height, form) (Moosavi, et al 2014). Poor atrium design could lead to stale, warm air from the lower floors recirculating and entering the upper floors connected to the atrium (Acred, A. and G. R. Hunt, 2013), resulting in poor air quality. It is thus common to disconnect the upper floors from the atrium allowing for air removal to be facilitated by a separate ventilation strategy, commonly comprising roof clerestories (Lomas, 2007).

Atria geometry, opening characteristics and roof properties in multi-storey buildings can affect thermal conditions and ventilation regime, which could be evaluated with regards to the natural ventilation performance and design using CFD and physical models (Chenvidyakarn, 2013). Doheim et al, (2013) using CFD examined the ventilation performance of three of the most common atrium configurations (i.e. square, rectangular and triangular prism) and predicted that the horizontal profile of atria is a vital performance factor and that the rectangular configuration contributed to improved performance.

Ga-Young et al, (2013) evaluated the natural ventilation performance of two types of inlet and outlet arrangements; parallel and diagonal, for use in double-skin facades. They found opening area and the increment depth can affect natural ventilation performance, can increasing airflow and ventilation rate throughout the room. Similarly, Abdullah, H. and H, Z,. Alibaba (2020) found openings in a cross-ventilation scenario significantly improved the natural ventilation performance of offices and were often less complex than singlesided arrangements. Nevertheless, smaller windows utilising single-sided ventilation could be more effective than a larger window and more effective than cross-ventilation of various window designs.

Nonetheless, the design process to arrive at a successful solution is a complex one, owing to uncertainties associated with office design, dynamic spatial characteristics of natural ventilation and lack of fully integrated design and modelling tools (Aldawoud, 2016; and Carrilho da Graca, G. and P. Linden, 2016). Nonetheless, computational fluid dynamics (CFD) and water-bath modelling (WBM) can be successfully used to investigate airflow distribution in occupied spaces, as demonstrated in literature (Linden et al, 1990; Todd, 2016; Chenvidyakarn, T. and A. Woods, 2005, 2010 and Short, C. and S. Al-Maiyah, 2009), whilst also validating both research methods. In light of this, water is often used as a working fluid at reduced-scale to model airflows, as using air creates greater discrepancies in comparison to those at full-scale (Chenvidyakarn, 2013). Also, the inclusion of an induced dyed salt solution in WBM significantly enhances the visualisation and digital capture of the flow characteristics providing higher levels of details regarding the results produced. 
Using physical models, Chenvidyakarn and Woods (2005 and 2010) evaluated the effect of opening height on a space interconnected to an atrium. Relationships between flow rates, air temperatures, heat inputs and building geometries, can be explored using simple mathematical models during preliminary design stages, particularly for the calculation of ventilation flow rates and effective openable areas (Acred, A. and G. R. Hunt, 2013, 2014, 2015). Hussain and Oosthuizen $(2012,2013)$ carried out numerical investigations of buoyancy-driven, natural ventilation performance and the metric of thermal comfort using a validated CFD model with the Shear-Stress Transport (SST) turbulence model. Buoyancy-driven, natural ventilation was able to provide acceptable comfort conditions inside an atrium building, proving the suitability of their methodology during early design stages to establish optimal atrium design.

At the forefront of recent successful, award-winning designs is the inclusion of high-aspect-ratio (HAR) façade openings to accommodate a new trend of perimeter building cores. This is an attempt to open up floor space, encourage collaborative working and enhance communication, in order to ascertain the productivity benefits associated with these characteristics. Building cores provide a vital means of vertical circulation, services, toilets and fire escapes; however, the investigation into their optimal positioning from a ventilation performance and engineering perspectives has yet to be carried out. Although poor design of openings, atria or building cores, could be detrimental to the intended airflow paths and distribution and to the thermal characteristics of the space, their combined ventilation performance in deep-plan spaces is yet to be explored.

This research focuses on the investigation of specific building elements (i.e. ventilation openings, atria and core design) in various combinations of deep, open-plan, naturally ventilated office typologies, with the aim of investigating the performance sensitivity of several proposed configurations for an acceptable internal thermal environment, in terms of air velocity, temperature distribution, and ventilation flow rates.

This research aims to investigate the ventilation performance of several proposed design configurations, combining various ventilation openings, atria and core designs in deep, open-plan, naturally ventilated office typologies, in order to ensure acceptable internal thermal environment, in terms of air velocity, temperature distribution, and ventilation flow rates. The investigation of the ventilation performance of HAR openings in a generic office environment was carried out using computational models and a novel WBM. To start, an archetypal building, which would be subjected to the alternative design parameters, was established. The WBM's form permitted several experiments to be performed, increasing the rigour of the validation process and resultant design guidance. The reasoning behind this was to obtain significant improvements in the amount of 
transient flow information, increasing the comprehension of the flow characteristics of natural ventilation, aiding the justification of design decisions.

The research outcome is advantageous in both ascertaining the optimum combination of, and highlighting airflow and thermal characteristics associated with, specific design parameters and decisions. Through innovative and original methods, this paper overcame perceived difficulties in the investigation and understanding of deep, open-plan, naturally ventilated office typologies. In addition to this, increased results reliability was attained through the utilisation of multiple CFD simulations that were rigorously validated with a complimentary novel WBM. In view of climate change and global warming, the utilisation of these original engineering solutions into the design and modelling procedure could significantly increase the adoption of iconic, low-energy, and natural ventilation designs.

\section{Research Methods:}

\subsection{Development of Archetypal building and design variables:}

In this study a base-case building design was developed in accordance with typical open-plan office typologies utilised by Foster + Partners and a number of variations were investigated. The parametrisation of specific building elements (core, atrium and opening design) created the 36 proposed combinations of various core, atria, and opening designs to be investigated in the parametric study. The ventilation performance of the base-case was evaluated using both steady-state CFD and WBM to provide the validated performance benchmark; only CFD analysis was performed for the remaining proposed 35 cases. Figure 1 shows the combinations of design variables in schematic form, illustrating the location of building cores, atria and occupied zone, as well as the four opening designs that were utilised. The design variables consisted of four variations of high-aspect-ratio (HAR) openings with a similar dimension to that of the floor-to-ceiling height, in either a mid-level vertical (MLV) or high-level horizontal (HLH) orientation, used in combination with three atrium and core designs.

The archetypal building comprises seven floors measuring $70 \mathrm{~m}$ length by $50 \mathrm{~m}$ depth and $36 \mathrm{~m}$ height with $2.90 \mathrm{~m}$ floor-to-ceiling height. The top floor was disconnected from the atrium; this meant two separate and independent ventilation exhaust methods were used, with the lower floors being connected to the atrium (lower computational domain) and the top floor being severed by roof lanterns (upper domain). For the base-case design, a $36 \mathrm{~m}$ high, $15.86 \mathrm{~m}$ square central atrium took up $12 \%$ of the floor plan, while the building cores occupied $10 \%$ of the floor plan. On all floors, high-level horizontal (HLH) unobstructed openings measuring 
$2.00 \mathrm{~m} \times 0.10 \mathrm{~m}(\mathrm{~L} \times \mathrm{W})$, with a sill height of $2.70 \mathrm{~m}$, provided the openable area for natural ventilation. All the above dimensions were obtained through liaison with architects, assessment of relevant building projects, alongside standards, recommendations and engineering rules-of-thumb (Van Meel et al, 2010; Korolija, 2013; Marmot and Eley, 2000).

Following the development of the base-case design, three further variations of core and atrium, and four alternative opening design combinations were proposed. Atrium designs comprised one central square (A1 $15.86 \times 15.86 \mathrm{~m})$, two square $(\mathrm{A} 2-13.40 \times 13.40 \mathrm{~m})$, and a singular rectangle $(\mathrm{A} 3-13.70 \times 26.20 \mathrm{~m})$, the height of the various atrium designs being consistent throughout. Building cores, measuring $10 \%$ of the floor plan, were positioned in a typical (C1) location, or adjacent to either the short (C2) or long (C3) façades (Figure 1); with areas of these elements being equal to that of the archetypal building. Four combinations of HAR openings were positioned on both the façades and atrium walls; these being high-level horizontal (HLH, $2.00 \mathrm{x} 0.10 \mathrm{~m}$ ) and mid-level vertical (MLV, $0.10 \times 2.00 \mathrm{~m}$ ), as shown at the bottom of Figure 1. A simple coding system was utilised to aid in the illustration of which variants comprised the simulation geometry, with each design containing an atrium $(A)$, core $(C)$ and opening $(\mathrm{O})$ design; for example $\mathrm{A}^{*} \mathrm{C}^{*} \mathrm{O} *$.

In an attempt to define the optimum configuration, it was necessary to alleviate complexities in the findings, as the results suggested discrepancies in the best performing design parameters when used in various combinations. The identification of the most influential design parameter (core, atrium or opening design) was made possible by examining cases which contained a singular design parameter change, this aiding in the understanding of which design parameters had the greatest effect on the thermal environment. Such analysis would form the foundation stating a more definitive optimum configuration, as well as highlighting the best performing variation of each individual design parameter.

The configuration containing the central square atrium (A1) and typical core (C1), served by the O1 opening combination, forms the base-case design. Additionally, the two core designs containing A1C*O1 (A1C2O1 and A1C3O1) would act as further benchmarks. These three scenarios create benchmark levels of performance for the entire study (A1C1O1), and each core design (A1C2O1 and A1C3O1). Reduced-scale WBM and CFD analysis were performed on the base-case, whereas the benchmark cases were only evaluated using CFD. 


\subsection{Computational modelling approach}

A combination of CFD and WBM was used to predict the fresh air temperature distributions of the cases investigated in this paper. Steady-state CFD analysis using ANSYS-CFX of the internal thermal environment of the 36 simulations was performed. A mesh sensitivity study was performed to determine the optimum mesh regarding the balance between computational accuracy and resources. Eight different mesh densities were investigated and analysed for the base-case geometry. The meshes were created using the global meshing tool in ANSYS-CFX and finalised using part-meshing parameters, enabling the creation of meshes with sufficiently varied densities. Finer cells were positioned near boundaries and heat sources where high variable gradients were expected. The quality of each proposed mesh was assessed using the pre-quality histogram tool in ANSYS and predicted results. Simulations were considered converged if the RMS (Root Mean Square) residual, which is obtained by squaring the sum of all residuals before taking the square root of the mean, is lower than $5.0 \times 10^{-4}$, or tightly converged if this value is less than $5.0 \times 10^{-6}$. The simulation imbalance percentage is the normalised sum for the flows in an equation and can also be used to assess convergence; it is recommended that this value be as low as possible $(<5 \%$ ) (ANSYS Inc, 2016). During the mesh sensitivity, the Shear Stress Transport (SST) two-equation and RNG turbulence models were investigated, as recommended in literature (Hussain, S. and P. H. Oosthuizen, 2012, 2013; ANSYS Inc, 2016). The meshes used along with their run time and normalised errors are shown in Table 1.

The computational domain was divided into two, in order to model separately but simultaneously the lower floors (lower domain) and the top floor (upper domain), which contained two independent ventilation strategies: the atrium and the roof clerestories. Table 1 shows the different properties of the meshes investigated of each of the two domains, and the percentage equation imbalance of each. Using the high-performance computer at Loughborough University, all run times were feasible, therefore, reducing the simulation equation imbalance of both domains was possible. All of the meshes produced a converged simulation. In order to understand and examine the effect of each of the investigated turbulence models, there was a small variation in the number of meshing elements between some cases (1 and 2, 5 and 6). With respect to this, mesh 5 achieved tighter convergence upon utilising the SST turbulence model, despite a longer but feasible run time. Mean room air temperatures at various heights throughout the simulation cases utilised in the mesh sensitivity were predicted through the positioning of a horizontal plane across the space at different heights. These results are collated in Figure 2 showing comparable values for meshes 3, 4, 5 and 6 across all heights. Despite meshes 1, 2, 7 and 8 
demonstrating some similarities at the middle heights, there was some divergence towards the extents (heights 0.1 and $1.7 \mathrm{~m}$ ). These discrepancies in the results were largely a result of the fineness of the mesh surrounding the perimeter of the office represented by the domain boundaries and the heat sources assigned to fictitious objects. Moreover, mesh 5 produced similar, very low percentage imbalances for both the lower and upper domains, meaning similar degrees of convergence were obtained in both domains (Table 1). Based on acceptable run time, convergence and pre-quality histogram results, mesh 5 was selected for the remaining simulations.

Table 1 -Mesh sensitivity results

\begin{tabular}{|l|l|l|l|l|l|}
\hline Mesh & $\begin{array}{l}\text { Turbulence } \\
\text { Model }\end{array}$ & $\begin{array}{l}\text { Top floor } \\
(\%)\end{array}$ & $\begin{array}{l}\text { Lower } \\
\text { floors }(\%)\end{array}$ & $\begin{array}{l}\text { Meshing } \\
\text { elements }\end{array}$ & Run time (s) \\
\hline 1 & SST & 0.15 & 1.66 & $14,323,307$ & 509135 \\
\hline 2 & RNG & 0.16 & 0.44 & $14,419,538$ & 185193 \\
\hline 3 & SST & 0.88 & 1.25 & $19,427,580$ & 401679 \\
\hline 4 & RNG & 0.22 & 0.79 & $19,427,580$ & 218344 \\
\hline 5 & SST & 0.004 & 0.05 & $22,459,099$ & 512013 \\
\hline 6 & RNG & 0.38 & 0.51 & $23,064,850$ & 291124 \\
\hline 7 & SST & 0.16 & 0.3 & $27,053,717$ & 584338 \\
\hline 8 & SST & 0.25 & 0.5 & $31,455,795$ & 509357 \\
\hline
\end{tabular}

The opening boundary condition was applied to all façade openings, acting as inlet and outlets, to predict the airflow characteristics across the building façade. This is based on the orifice plate equation (Eq 1) and calculates the magnitude and direction of the fluid across the opening using pressure differentials, depicted by temperature differentials at the boundary location. A ventilation rate of $10.501 / \mathrm{s} \mathrm{pp}(2.20 \mathrm{ACH})$ (ANSI/ASHRAE Standard 62.1, 2013) was used to calculate the required openable area for the space. This flow rate was converted and inputted into Eq 1 which was rearranged to allow the openable area to be calculated. Airflow rate $\left(Q \mathrm{~m}^{3} / \mathrm{s}\right)$, through an opening is determined by the openable area $\left(A_{f} \mathrm{~m}^{2}\right)$, the pressure difference across the opening $(\triangle P \mathrm{~Pa})$, the density of air $\left(\rho \mathrm{kg} / \mathrm{m}^{3}\right)$ and the geometry of the openings. The effect of the opening geometry on flow is accounted for with the inclusion of the dimensionless discharge coefficient $\left(C_{d}\right)$. A value of 0.61 is typically used and is stated to replicate flow contraction and pressure loss across a sharp-edged orifice; this value is recommended in literature (ANSI/ASHRAE Standard 62.1, 2013).

$$
Q=C_{d} A_{f} \sqrt{\frac{2 \Delta P}{\rho}}
$$

For simplicity, climatic conditions were kept constant, with an ambient temperature being set at $24^{\circ} \mathrm{C}$ to represent an average warm summers day in a temperate climate. Due to the comparative nature of the study and 
research methods employed, and with the focus being on the thermal environment, other elements such as relative humidity, $\mathrm{CO}_{2}$ levels and wind where not included. Subsequently, the results would be applicable to similar environments; however, the methodologies utilised are not geographically restricted. Turbulence intensity at the openings was set at $5 \%$ to depict a medium turbulent case, such as natural ventilation (Aldawoud, 2016 and ANSYS Inc., 2016). The no-slip boundary condition was assigned at all solid boundaries, in order to model the rapid variation in fluid properties close to solid boundaries. This condition implies that the temperature gradient is 0 at the wall; however, for the velocity field, the no-slip condition implies a high velocity gradient exists in this region.

Representative internal office heat gains and occupancy density were obtained from documentation produced by the British Council for Offices and other relevant studies (Korolija, 2013; Ravikumar, P. and D. Prakash, 2009; and Chalkias, 2014). An occupancy density of $10.5 \mathrm{~m}^{2}$ per person was chosen. To simplify the model and comparison process, the effects of solar gains throughout the entire model were disregarded and it was only heat gains from individual occupants and equipment which were collectively assigned and disseminated to objects (8 $\mathrm{W} / \mathrm{m}^{2}$ desks), façades $\left(4 \mathrm{~W} / \mathrm{m}^{2}\right)$, ceilings $\left(2 \mathrm{~W} / \mathrm{m}^{2}\right)$ and floors $\left(3 \mathrm{~W} / \mathrm{m}^{2}\right)$. The internal atrium and core walls were assigned the adiabatic boundary condition, meaning no heat flux was assigned to them. The heat flux from facades $\left(4 \mathrm{~W} / \mathrm{m}^{2}\right)$ varied to allow the total heat flux assigned to be consistent across designs despite variations in available façade space due to core location. To improve simulation juxtaposition no solar gains and heat transfer across the atrium was present. The CFD geometry of the base case is shown in Figure 3.

To reduce modelling complexities, in the validation study, only heat gains assigned to desks were included in the validation experiments. In WBM the heat sources were replicated by a buoyancy flux produced by the flow of dyed salt-solution from the nozzles, whereas in the CFD this was done by assigning heat fluxes to objects replicating desks. Consequently, the calculated openable area and temperature difference being modelled drives the amount of flow throughout the model.

Thermal comfort was evaluated in each design according to absolute internal air temperatures and vertical temperature gradients with regard to adaptive standards CEN 15251 and ISO 7730 (BSI, 2007; ISO 7730, 2005), as well as considering air temperature distribution throughout the office. Firstly, with regards to vertical temperature stratification, this was calculated through the placement of temperature contours spanning various 
office floor plan depths (shallow 0-5m, medium-deep 5-10m, deep 10-15m and very-deep >15m) and at different heights $(0.1,0.6,1.1$ and $1.7 \mathrm{~m}$ above floor level) of interest in accordance to CIBSE Guide (CIBSE AM10, 2014) and relevant standards (BSI, 2007; ISO 7730, 2005; and ANSI/ASHRAE Standard 62.1, 2013) representing the height of an ankle, abdomen, and head of a seated and standing person. Three distinct comfort categories are stated in ISO 7730 (2005); these categories are used to depict the thermal quality of the environment with I being the best and III being the worse. Secondly, in naturally ventilated buildings, thermal discomfort could be perceived when the internal temperature is $4^{\circ} \mathrm{C}$ above ambient, this is in line with the $80 \%$ acceptability upper limit in adaptive standard CEN 15251. These allowed the overall temperature (overheating threshold) and temperature variations (temperature stratification/distribution) to be rigorously examined. In addition to this, building and floor averaged ventilation flow rates were calculated for all 36 designs and juxtaposed with rates stated in CIBSE AM10 (2014) (the 10.5 1/s per person value used to calculate the openable area) and ASHRAE [25] for fresh air requirements, and those contained in previous studies (Fisk, W. J. and A. H. Rosenfeld, 1997; Wargocki et al, 2002; Chenari, 2016; and Wyon, 2004) to provide cooling and ascertaining increased productivity and health benefits.

\subsection{Model verification using water-bath modelling}

Complimentary water-bath modelling (WBM) experiments were performed on a 1:30 reduced-scale, perspex replica model of the base-case design modelled in CFD. This scale along with some geometrical simplifications were necessary in order to accommodate the model in the available tank, whilst still providing sufficient model height to allow flow development; as a result, a quarter of the ground floor and atrium was represented. The section of the full-scale CFD model being represented by the WBM is shown in Figure 4, whereas Figure 5 shows the WBM in-situ. The primary purpose of the WBM experiments was to validate the CFD simulations however, these produced vital transient natural ventilation flow data. To reduce modelling complexities, in the validation study, only heat gains assigned to desks (representing occupant positions in the space) were included. In WBM the heat sources were replicated by a buoyancy flux produced by the flow of dyed salt-solution from the nozzles, whereas in the CFD models this was done by assigning heat fluxes to objects replicating desks. Consequently, the calculated openable area and temperature difference being modelled determines the amount of flow throughout the model.

In total, six experiments were conducted using both WBM and CFD to evaluate different heat source scenarios in the base-case geometry (Figure 6), representing the locations at which occupants and equipment were located; 
these were then recreated in the full-scale in the CFD. The foremost focus of this original utilisation of WBM; performing multiple experiments on a singular model, is to significantly increase the amount of transient validation data for comparison with the steady-state CFD results. Furthermore, a by-product of this gave the opportunity to explore the effect of variations in distance between heat source(s) to outlet, as well as the quantity of heat sources themselves. The transient data from the WBM allowed the development of any thermal stratification to be visualised. As a result, the rigor of both the validation and overall study was improved, also providing complimentary highly detailed steady-state and transient flow information.

The WBM utilised a novel pumping, piping and nozzle arrangement in order to allow various experimental cases to be performed. This set-up allowed the model to stay in-situ whilst required flow volume and point of delivery adjustments/alterations were performed. The nozzles attached to the model were supplied with gravity fed flow of dyed salt-solution supplied by the pumping and piping system. This created the essential turbulent flow into the model, thus satisfying the requirements of plume theory to reliably represent natural ventilation flows. Two valves and a four-way splitter were connected to the overflow pipe, which aided flow control and diversion (Figure 7), thereby making it possible to supply the model with flow from different locations and in various combinations; thereby, making it possible to supply the model with flow from different locations and in various combinations.

A 30-litre tank at ground level allowed the addition of salt and food dye, and the volume of water in the system to be maintained. This salt-solution is then pumped into a header tank positioned $3.50 \mathrm{~m}$ above floor level, providing constant mixing of salt-solution, thus preventing any settling of salt in either of the tanks. A pipe attached to the header tank supplied the perspex model which was immersed in the water bath $(1.00 \mathrm{~m} \times 1.40 \mathrm{~m} \times$ $1.60 \mathrm{~m}$ ) with the required gravity fed flow. Several scale rules were positioned on the sides of the model to facilitate measurement of interface heights and add dimensions to airflow and temperature phenomena. Transient characteristics were captured using digital photography. This was achieved using a DSLR camera positioned on a tripod aligned perpendicular to the working section of the model (Figure 8).

\section{Results and Discussion:}

Although the following discourse focuses on the archetypal building, the resultant flow characteristics associated with the implementation of the variations in opening designs would be expected to be consistent in various building types. The discussion and results explore the implications of the several proposed opening 
design combinations, which could aid in the justification of design decisions of future naturally ventilated buildings with a focus on enhancing the thermal environment.

\subsection{Validation results:}

Evaluation of both the CFD and WBM geometries of the base-case were evaluated using both quantitatively (predicted interface height) and qualitatively (flow patterns) data. The juxtaposition of the CFD and WBM results, produced by the two modelling techniques, along with the inclusion of plume theory, confirmed dynamic similarity had been ascertained between the two modelling techniques. This was evidenced through the prediction of comparable interface heights of a band of fluid (replicating warmer air) and flow phenomena formed. The interface is defined as the height at which the distinct separation between a band of dyed salt solution (replicating warmer air) and clear (fresh) water occurs.

A number of validation experiments using WBM, were performed until steady-state was reached. In addition to this, experiments concerning variations in the strength and location of heat source(s) were carried out. Experiments can be seen in schematic form in Figure 6, which illustrates the variations in heat source location depicted by the active nozzle (red triangle), openings and the model itself. As shown in Figure 9, the lower section containing the represented heat sources of all WBM experiments maintained a light shade of saltsolution and interface heights were clearly discernible. Predicted interface heights from these experiments are shown as measured and as a percentage of floor-to-ceiling height in Table 2. Similar interface heights of 52\% (CFD) and 50\% (WBM) of floor-to-ceiling height were predicted. These errors varied between 1 and 7\% (Table 2).

Table 2 - Comparison of interface height predictions between CFD and WBM.

\begin{tabular}{|l|l|l|l|l|l|}
\hline Experiment & $\begin{array}{c}\text { CFD } \\
\text { Interface } \\
\text { height } \\
(\mathrm{m})\end{array}$ & $\begin{array}{c}\text { WBM } \\
\text { interface } \\
\text { height } \\
(\mathrm{cm})\end{array}$ & $\begin{array}{c}\text { CFD } \\
\text { (Normalised } \\
\text { interface } \\
\text { height })\end{array}$ & $\begin{array}{c}\text { WBM } \\
\text { (Normalised } \\
\text { interface } \\
\text { height) }\end{array}$ & Error (\%) \\
\hline $\begin{array}{l}\text { Base-case } \\
\text { Case A }\end{array}$ & 1.53 & 4.50 & 52 & 50 & 2 \\
\hline Case B & 2.00 & 5.50 & 68 & 61 & 7 \\
\hline Case C & 1.79 & 6.10 & 62 & 67 & 5 \\
\hline Case D & 1.70 & 6.00 & 59 & 60 & 1 \\
\hline Case E & 1.85 & 5.50 & 64 & 61 & 3 \\
\hline
\end{tabular}


Predicted interface heights from the WBM experiments and CFD simulations are compared in Figure 9. This is done through the analysis of digital photography from the WBM and temperature distributions obtained from the CFD simulations. A trend throughout all experiments was the clear formation of an interface with the creation of a protuberance downwards directly above the active nozzle. The occurrence of this was shown to be greater as the distance between the heat source and atrium increased, as demonstrated by the darker area of red on the CFD contours and darkness of the salt-solution in the WBM (Figure 9b). As this distance increases the interface becomes more blurred, suggesting increased mixing and exchanges of fluid across this interface. These phenomena would likely lead to warmer, potentially poorer quality air, being entrained downwards to lower levels and pervading the occupied zone. This less prominent, lower interface is highlighted by the second dashed line in figure $9 \mathrm{~b}$. The cause of this is could be the increased time the air spends in the space before being exhausted.

Both models revealed turbulent areas below the interface and are highlighted by blue rectangles (Figure 9a). These occurred when warmer air entering the atrium, and disturbing the layer of thermal stratification, as the airflow is influenced by several factors; these being, the two openings, heat sources and atrium in this region of the models. Particularly in the WBM where it was shown how the flows from the two openings sank, penetrated the interface, and was drawn into the plumes created by the heat sources. This increased the amount of mixing, and perceived air movement, which aided in lowering the adjacent air temperature. The use of elevated air movement, especially in natural ventilation, is a significantly favourable low-energy means of providing occupancy cooling.

Examination of the results from the two modelling techniques shown many similarities in normalised interface height and other flow phenomena, suggesting the implementation of the scaling and simplifications of the two models had a negligible effect on the IEQ data. Therefore, it was concluded that the CFD model was capable of predicting a reliable representation of the airflows and thermodynamics of the natural ventilation strategy.

\subsection{CFD evaluation of the internal thermal environment: horizontal and vertical}

\section{temperature distribution}

Throughout the study the examination of the internal thermal environment was performed regards to CEN 15251 and ISO 7730. Investigations focus on absolute temperatures (CEN 15251) and thermal variations in both a horizontal and vertical direction (ISO 7730), which have been reported to cause discomfort in naturally 
ventilated spaces. Mean absolute temperatures throughout the occupied zone gave an indication into the percentage of occupants perceived to be satisfied with the thermal environment; this would be $90 \%$ and $80 \%$ at temperatures $3^{\circ} \mathrm{C}$ and $4^{\circ} \mathrm{C}$ above the ambient respectively.

The base-case (A1C1O1) and two benchmarks (A1C2O1 \& A1C3O1), along with all $\mathrm{C} 1$ and $\mathrm{C} 2$ cases served by HLH (O1/O3) openings showed potential overheating, approaching the $80 \%$ acceptability limits by approximately $0.5^{\circ} \mathrm{C}$. Overall, whole-building collective averages are as follows; $3.6^{\circ} \mathrm{C}(\mathrm{C} 1)$ and $3.3^{\circ} \mathrm{C}(\mathrm{C} 2$ and C3), with temperatures associated with the C3 being predicting within the $80 \%$ acceptability limit (Figure 10). Designs which included $\mathrm{C} 1$ or $\mathrm{C} 2$ with either an A1 or A2 design often implied poor ventilation performance.

The prediction of higher occupied zone temperatures in the HLH (O1/O3) opening cases of approximately $1.80^{\circ} \mathrm{C}$, in comparison to the MLV $(\mathrm{O} 2 / \mathrm{O} 4)$ cases, suggests higher ventilation performance of openings in a vertical orientation $(\mathrm{O} 2 / \mathrm{O} 4)$. In general, an acceptable thermal environment was predicted in the majority of cases as temperatures often fell below the $4^{\circ} \mathrm{C}$ above ambient limit, meaning at least $80 \%$ of occupants would be perceived satisfied.

The results suggested some variability in the optimal configuration, as different combinations of design parameters proposed differences in the thermal environment. This was evidence as the results implied the worse performing core design for the MLV $(\mathrm{O} 2 / \mathrm{O} 4)$ cases was $\mathrm{C} 3$, despite this being the best performing when used in combination with HLH (O1/O3) openings (Figure 11). Such observations increase the complexities in the definition of an optimum configuration but reinforce the need for a rigorous study comprises many parameterised design features.

With regard to atrium design, A1 performed best with $\mathrm{C} 3$ as evidenced by the prediction of lower temperatures; the lowest of these being $3.09^{\circ} \mathrm{C}$ (above ambient) when $\mathrm{A} 1$ was employed. Despite this value being almost $1^{\circ} \mathrm{C}$ lower than the overheating threshold (CIBSE AM10, 2014) it is only $0.60^{\circ} \mathrm{C}$ lower than the highest calculated collective average for this atrium design (A1). 
Façade opening design created large fluctuations in ventilation performance, around $1.96^{\circ} \mathrm{C}$, regarding occupied zone air temperature, this change was more significant than a change in atrium design; this being $0.53^{\circ} \mathrm{C}$. Therefore, the effect that the opening design has on the air temperature in the occupied zone is nearly 3.7 times that of the atrium design. Overall, the best performing variant of each design parameter was A1, C 3 and O2. In comparison with the base case and two benchmarks, as temperature reductions of $2.65^{\circ} \mathrm{C}, 2.82^{\circ} \mathrm{C}$ and $2.03^{\circ} \mathrm{C}$ respectively, were predicted (Figure 10). Furthermore, the significant difference between the first two columns on the graph evidenced a reduction of $2.65^{\circ} \mathrm{C}$ within the occupied zone between configurations $\mathrm{O} 1$ and $\mathrm{O} 2$ (Figure 10).

In all cases the largest horizontal temperature variation at lower levels ( $<$ seated abdomen height) was between $0.75^{\circ} \mathrm{C}$ and $1.60^{\circ} \mathrm{C}$. However, values of $0.28^{\circ} \mathrm{C}(\mathrm{A} 3 \mathrm{C} 3 \mathrm{O} 2)$ and $2.03^{\circ} \mathrm{C}(\mathrm{A} 1 \mathrm{C} 1 \mathrm{O} 1)$ appeared out of this range (Figure 12). The results concerning O1 were similar to those of O3 due to both containing the MLV façade opening design. Furthermore, the $\mathrm{C} 1$ results are a good demonstration of how the air attaches itself to the core walls, which was consistent throughout the other proposed core designs. With regards to the base-case, the contours revealed the core was surrounded by cooler air that circumvented the occupied zone, leading to the largest recorded desk-height temperature gradient of $2.03^{\circ} \mathrm{C}$ from façade to the centre. This was common in the majority of cases and is illustrated by the areas of light green contours. The likely cause of this could be either the entrainment of supply air entering into a small space or the lack of heat flux into this space. In the cases containing compact atrium designs (A1 and A2), visible flows of cooler air can be seen to pass through the core and towards the atrium, however, these do not appear from the openings located on the long façades. This, along with the presence (or prediction) of excessive air velocities of cooler downdraught air caused by large temperature differences between the supply air and room air, causes significant temperature variations, which could lead to thermal discomfort. These supply airflows from the long façade of the HLH (O1/O3) cases evade perimeter areas close to the long facades (Figure 12), which are beneficial in ventilating the deeper zones of the office; however, these potentially bypass occupants near to the façade.

The demonstration of a uniform temperature throughout the office in the HLH (O1/O3) cases, suggest the supply air pervades the majority of the office, including areas close adjacent to all facades, as indicated by minimal colour variation on the contours (Figure 12). The combination of the perimeter core design and the rectangular atrium (A3) created shorter and more direct flow paths between façades and atrium throughout the 
space. However, it is only in these cases that there appears to be an accumulation of heat surrounding the desks due to these flows potentially entraining heat as they travel towards the atrium.

The air temperature contours in Figure 12 imply A1C1O2 provided cooler temperatures, less variable temperatures throughout the office. It was in the $\mathrm{A} 2 \mathrm{C} 1 \mathrm{O} 1$ where cooler streams of air from façade openings are predicted. Likewise, in the other HLH (O1/O3) cases, supply airflow plumes were not apparent, largely due to the height of the contours. Horizontal temperature differences were shown to diminish at different heights; $0.6 \mathrm{~m}$ $(\mathrm{O} 1 / \mathrm{O} 3)$ and $1.1 \mathrm{~m}(\mathrm{O} 2 / \mathrm{O} 4)$ above floor level. A possible cause of this is the airflow patterns and distribution throughout the office. However, absolute temperatures were much higher considering the HLH (O1/O3) cases in comparison to MLV (O2/O4). HLH (O1/O3) openings created a constricted flow vertically, in contrast to O2/O4 openings, leading to a well-mixed environment regarding room air temperature.

Temperatures approaching the overheating threshold and minimal air movement $(<0.10 \mathrm{~m} / \mathrm{s})$ were predicted close to the facades and in the medium-deep zones of the HLH (O1/O3) cases, despite a $33 \%$ reduction in vertical temperature difference between ankle and head height, in comparison to MLV (O2/O4) cases. In these zones, temperature differences approaching $1{ }^{\circ} \mathrm{C}$ were shown to reduce to $0.65^{\circ} \mathrm{C}$ as office depth increased; values of which would be regarded as acceptable by relevant standards and achieving the highest comfort category (BSI, 2007; ISO 7730, 2005; CIBSE AM10, 2014; and ANSI/ASHRAE Standard 62.1, 2013).

On the top floor, there was a clear difference in both mean ventilation rate and air temperature within the occupied zone (Figure 13). With regard to the MLV (O2/O4) openings, air can clearly be seen to enter into the space from the lower sections of the openings; this is not apparent in the HLH (O1/O3) cases. In comparison to $\mathrm{HLH}(\mathrm{O} 1 / \mathrm{O} 3)$, the implementation of $\mathrm{MLV}(\mathrm{O} 2 / \mathrm{O} 4)$ openings leads to a $3{ }^{\circ} \mathrm{C}$ temperature reduction.

There was a trend of differences regarding thermal stratification, occupied zone air temperature and the height at which supply air entered the space, between the two opening designs (Figure 13). The height at which supply air was delivered into the space was found to be a significant influencing factor in relation to the characteristics of thermal stratification. Supply air from the lower sections of the MLV (O2/O4)openings, lead to cooler temperatures at lower heights; these can be seen on the ground and third floors as the contours passed through the centre of façade openings on these floors (Figure 13). It can be seen in the HLH (O1/O3) cases how this 
supply plume of cooler air falls directly on the first row of desks, potentially leading to thermal discomfort and excessive air velocities.

The low-level supply of air (O2/O4) cooled most of the occupied zone, whereas the high-level delivery of air $(\mathrm{O} 1 / \mathrm{O} 3)$ disturbs this band of warmer air bringing this downwards, increasing the temperature of the space. In the MLV (O2/O4) cases, this was shown by the CFD contours to extend downwards, creating a significant thermal gradient throughout the occupied zone, sometimes exceeding the $3^{\circ} \mathrm{C}$ limit in ISO 7730 (2005). Consequently, these pose the largest risk of thermal discomfort, despite horizontal temperature gradients being shown to decrease as height above floor level increased.

Thermal distribution and stratification results infer $\mathrm{A} 1 \mathrm{C} 1 \mathrm{O} 1$ and $\mathrm{A} 1 \mathrm{C} 1 \mathrm{O} 3$ were the worst performing cases, as demonstrated by the formation of a thick band of warmer air towards the ceiling of office floors, which was predicted to obtrude downwards into the occupied zone (Figure 13). This trend of thermal characteristics was consistent throughout most of the HLH (O1/O3) cases. Despite thermal stratification being prominent in A1C1O2 case, the locality of the volume of warmer air was predicted above the occupied zone, therefore this potentially lower quality air would not impact occupant comfort; thus replicating the intended ventilation regime of buoyancy driven ventilation systems, displacing warmer, stale air towards the ceiling and out of the occupied zone (breathing zone). The occupied zone of this case and the other MLV $(\mathrm{O} 2 / \mathrm{O} 4)$ cases were shown to contain comfortable temperatures below the overheating threshold. Results implied that this thermal stratification could be alleviated through the implementation of $\mathrm{HLH}$ openings on the atrium walls (O4), evidenced by comparing the $\mathrm{A} 1 \mathrm{C} 1 \mathrm{O} 2$ and $\mathrm{A} 1 \mathrm{C} 1 \mathrm{O} 4$ contours. From this it can be seen how the thick band of warmer air is almost entirely absent in this case, suggesting no accumulation of warmer air at high level. This could be a result of the highlevel openings being positioned within this layer, assisting the warmer, buoyant-air leaving the space, as it rises and moves horizontally at ceiling level toward the opening. Whereas, in the MLV (O2/O4) cases this band had to extend downwards in order to leave the space, thus the creation of an accumulation of heat above the height of the opening.

In general, for the results showed that the better performing cases comprised HLH openings; these being $\mathrm{A} 2 \mathrm{C} 1 \mathrm{O} 3, \mathrm{~A} 2 \mathrm{C} 2 \mathrm{O} 3, \mathrm{~A} 2 \mathrm{C} 3 \mathrm{O} 1$ and $\mathrm{A} 2 \mathrm{C} 3 \mathrm{O} 3$. Vertical temperature differences were around $0.8^{\circ} \mathrm{C}$ for the worst and $0.25^{\circ} \mathrm{C}$ for the better performing cases; in these, it was common for $\mathrm{A} 2$ and $\mathrm{A} 3$ to be employed. Therefore, 
HLH façade openings, in combination of either the A2 or A3, achieve the highest comfort category regarding thermal stratification (ISO 7730, 2005), albeit at higher temperatures than those produced by the MLV cases.

\subsection{Predicted ventilation flow rates}

It was predicted that whole-building averages from simulations containing a specific designs parameter regarding variants of opening and atrium design exceeded the target relative ventilation rate of $2.2 \mathrm{ACH}$; collective averages for $\mathrm{C} 1, \mathrm{C} 2$ and $\mathrm{C} 3$ were $2.44,2.41$ and $2.32 \mathrm{ACH}$, respectively (Figure 14). These predictions were largely influenced by the implementation of MLV façade openings. The move from $\mathrm{C} 1$ and $\mathrm{C} 2$ to $\mathrm{C} 3$, increased the distance between facade openings and the atrium, leading to a reduced entrainment effect of the atrium, and lower ventilation rates. In the $\mathrm{C} 2$ cases, the majority of façade openings are closer to the atrium, leading to a shorter inlet-to-outlet distance and to the atrium being directly accessible to the façade openings. Subsequently, when used with MLV openings, ventilation rates were shown to exceed $2.50 \mathrm{ACH}$.

In the $\mathrm{HLH}(\mathrm{O} 1 / \mathrm{O} 3)$ cases, ventilation rates decreased by approximately $0.30 \mathrm{ACH}$, meaning they often fell below the target value (2.20 ACH). Supply flows from these openings were shown to enter deeper into the office and at a higher rate than the MLV (O2/O4) cases. This aided in ventilating deeper zones of the office, however, when the office configuration led to a reduced inlet-to-outlet distance, supply air potentially circumvented the occupied zone. The results showed $\mathrm{C} 1$ to be the best performing, although further improvements were demonstrated when $\mathrm{C} 2$ cases were served by MLV (O2/O4) façade openings (Figure 14a). Although the optimal configuration would be a $\mathrm{C} 2$ office served by MLV (O2/O4) façade openings, regardless of atrium design. However, concerning all atrium designs, $\mathrm{C} 1$ is shown to be the best performing core. This is despite results showing there to be minimal variation upon an alteration in core design, as evidenced by negligible performance variations in the majority of cases, especially concerning A3 (Figure 14b).

Ventilation rates above $2.5 \mathrm{ACH}$ were predicted in eight of the 36 cases; the highest being $2.62 \mathrm{ACH}$ (A2C2O2). $\mathrm{A} 1 \mathrm{C} 2 \mathrm{O} 2$ and $\mathrm{A} 3 \mathrm{C} 2 \mathrm{O} 2$ showed rates approaching $2.60 \mathrm{ACH}$; both of these cases contained the $\mathrm{O} 2$ opening design. However, $\mathrm{A} 1 \mathrm{C} 1 \mathrm{O} 3, \mathrm{~A} 2 \mathrm{C} 2 \mathrm{O} 1$ and $\mathrm{A} 2 \mathrm{C} 2 \mathrm{O} 3$, contained rates akin to the $\mathrm{O} 2 / \mathrm{O} 4$ cases despite HLH façade openings being employed. Collective averages suggested there is no optimal core design, nevertheless, it was common for $\mathrm{C} 2$ to be present in the better performing cases. Concerning these findings, in order to achieve the higher ventilation rates, configurations should stem from the utilisation of $\mathrm{C} 2$ and $\mathrm{O} 2$ (Figure 15). 


\subsection{Effect of air removal method on ventilation performance}

Average values for each opening design regarding occupied zone air temperatures and ACH averages representing the sets of floors served by both ventilation exhaust methods (atrium and roof lanterns), were plotted (Figure 16). The MLV (O2/O4) openings results suggested superior performance over HLH (O1/O3), as evidenced by the prediction of $3.00^{\circ} \mathrm{C}$ lower temperatures. With respect to the sets of floors, these were calculated to be $3.24^{\circ} \mathrm{C}(\mathrm{LF})$ and $2.71^{\circ} \mathrm{C}(\mathrm{TF})$ for $\mathrm{O} 2$ and $3.26^{\circ} \mathrm{C}(\mathrm{LF})$ and $2.78^{\circ} \mathrm{C}$ (TF) for $\mathrm{O} 4$, all appearing below the overheating threshold. This was not true for HLH façade openings, as collective averages were calculated to be $4.20^{\circ} \mathrm{C}$ (Figure 16a). Performance differences between the two groups of floors in these cases were shown to be far greater as ventilation rates on the top floor were calculated to be on average $0.80^{\circ} \mathrm{C}$ less than those on the lower floors. For $\mathrm{MLV}(\mathrm{O} 2 / \mathrm{O} 4)$ openings this reduction was around $0.17 \mathrm{ACH}$, thus a consistent performance irrespective of the ventilation exhaust method, was implied. The relative rates used in the calculation of these performance differences were on average $0.33 \mathrm{ACH}$ higher than that of the identical HLH (O1/O3) case (Figure 16b).

The performance patterns associated with occupied zone air temperatures were similar to those relating to $\mathrm{ACH}$, as the MLV cases were shown to be superior, providing rates which exceeded the target value of 2.20 ACH. Also shown was the sub-standard performance of HLH (O1/O3) openings, especially on the top floor of these cases. Despite this, the collective average for $\mathrm{O} 3$ cases is only $0.19 \mathrm{ACH}$ below the target value (Figure 16b).

In comparison to the base-case (A1C1O1) and two Benchmarks (A1C2O1 and $\mathrm{A} 1 \mathrm{C} 3 \mathrm{O} 1)$, only the lower floors of $\mathrm{A} 1 \mathrm{C} 3 \mathrm{O} 1$ were predicted not to overheat; potentially a result of the openness of the office configuration as $\mathrm{C} 3$ was installed. $\mathrm{A} 1 \mathrm{C} 3 \mathrm{O} 2$ showed lower floor temperatures of $1.84^{\circ} \mathrm{C}$ above ambient, this being $0.81{ }^{\circ} \mathrm{C}$ less than the next best performing ( $\mathrm{A} 1 \mathrm{C} 3 \mathrm{O} 4)$ and around $1.55^{\circ} \mathrm{C}$ lower than the other $\mathrm{C} 3$ cases. These temperatures were $2.37^{\circ} \mathrm{C}(\mathrm{LF})$ and $2.03^{\circ} \mathrm{C}(\mathrm{TF})$ lower than the Base-case, and $2.06^{\circ} \mathrm{C}(\mathrm{LF})$ and $1.84^{\circ} \mathrm{C}(\mathrm{TF})$ in comparison to the C3 Benchmark (Figure 17a). This indicates that the proposed designs enhanced the cooling potential of the ventilation strategy. However, this would require appropriate control measures in winter to ensure sufficient ventilation was supplied without over cooling the space.

Overall, for HLH openings, collective occupied zone air temperature averages above ambient temperature were $3.92^{\circ} \mathrm{C}(\mathrm{LF})$ and $4.48^{\circ} \mathrm{C}(\mathrm{TF})$, and $3.25^{\circ} \mathrm{C}(\mathrm{LF})$ and $2.74^{\circ} \mathrm{C}(\mathrm{TF})$ for $\mathrm{MLV}$, revealing a significant performance difference between the two opening designs for the two different sets of floors. For the majority of the HLH cases, overheating by an average of $0.48^{\circ} \mathrm{C}$ was predicted on the top floors, with lower floor temperatures 
$\left(3.92^{\circ} \mathrm{C}\right)$ approaching the overheating threshold $\left(4.0^{\circ} \mathrm{C}\right)$. The calculation of average temperatures of $3.25^{\circ} \mathrm{C}(\mathrm{LF})$ and $2.74^{\circ} \mathrm{C}(\mathrm{TF})$ implied comfortable temperatures in all of the MLV cases (Figure 17a). It was therefore deduced that although the lower floors of the HLH cases were deemed comfortable, MLV were still shown to give better performance across both sets of floors.

Ventilation rates on the lower floors were $0.48 \mathrm{ACH}$ less than the top floor, evidencing significant ventilation performance variation between the sets of floors (Figure 17a). This was not the case for A1C3O2 and A1C3O4 as higher rates were predicted on the top floor. The suggested reason behind this is likely to stem from the similar performance on both groups of floors when MLV (O2/O4) openings were used. Throughout this research the results predicted higher ventilation rates were predicted on the lower floors than the top floor. However, with regard to this opening design $(\mathrm{O} 2 / \mathrm{O} 4)$, the previous performance reduction between the two groups of floors of 0.48 ACH, was now calculated to be $0.17 \mathrm{ACH}$ (Figure 17b), but 0.80 ACH for HLH (O1/O3) openings. The top floor of these cases often contained insufficient ventilation. Therefore, in order to achieve near similar, sufficient ventilation rates $(2.20 \mathrm{ACH})$ on all floors, the utilisation of MLV (O2/O4) openings should be considered.

Despite this, an average 0.05 ACH difference between the two opening designs suggests similar results on the lower floors. The results suggest that $\mathrm{MLV}(\mathrm{O} 2 / \mathrm{O} 4)$ is the optimal opening design, as sufficient ventilation was predicted regardless of the means of air removal; atrium or roof lanterns (Figure 17b). The superior performance of $\mathrm{O} 2 / \mathrm{O} 4$, in comparison to $\mathrm{HLH}(\mathrm{O} 1 / \mathrm{O} 3)$ on the top floor (in combination with high level outlets), was demonstrated by a lower average top floor temperature of $2.74^{\circ} \mathrm{C}$. Furthermore, it was common for the best performing designs to include the $\mathrm{C} 3$ design. It is, therefore, unsurprising that the results affirm $\mathrm{A} 1 \mathrm{C} 3 \mathrm{O} 2$ to be the optimal combination of design parameters.

\subsection{Discussion}

Tabulating average air temperature and $\mathrm{ACH}$ values for each parameterised design characteristic provides a compendium of the main findings, focusing on variations between the lower and upper floors, mean room air temperatures and thermal distribution for each design parameter (Table 3).

Firstly, there is little performance variation for atrium and core design, unlike opening design. However, MLV $(\mathrm{O} 2 / \mathrm{O} 4)$ openings provided higher ventilation rates of around $0.3 \mathrm{ACH}$ in comparison to HLH. Nevertheless, 
there is a consistent trend of lower ventilation rates on the upper floors across all design parameters, with the lowest ventilations rates observed for the $\mathrm{O} 1 / \mathrm{O} 3$ cases, of approximately $1.0 \mathrm{ACH}$.

Secondly, thermal distribution results comprising air temperatures from various office depths and heights, had a similar trend $\mathrm{ACH}$ predictions. The opening designs allowed for more noticeable but comfortable air movement and flows to be established in the occupied zone, with MLV providing superior cooling potential over HLH. The temperature was shown to vary most noticeably in the shallow regions and lower heights of the office, with these varying by approximately $1^{\circ} \mathrm{C}$ between the MLV and HLH designs, significantly affecting any occupants adjacent to the facades. Despite this, there appears to be little difference in vertical and horizontal airflow throughout the occupied zone. Air temperature rose from the façade to the centre of the office; however, this rise was almost $1^{\circ} \mathrm{C}$ higher for the HLH designs. Indoor air temperature and fresh air distributions varied

significantly between MLV and HLV; the design of façade openings is the most influential design parameter on the building's ventilation performance. The implementation of a perimeter core (C2 and C3) and a central atrium produced an improvement in ventilation performance; however, regarding the atrium this was often negligible. This was despite the CFD results suggesting the atrium shaped as the building's footprint created a uniform environment with regards to air temperatures and velocities. Additionally, the top floor that was disconnected to the atrium but had roof clerestories and HL openings, would require further design investigation to reduce the currently predicted higher temperatures and lower ventilation rates than the rest of the building. Through this study, it was predicted that the most optimum office design would encompass a perimeter core (C2 and C3) and centralised atrium supplied with MLV openings.

\section{Conclusions}

The research presented here focused on the parameterisation of building and ventilation elements (atrium, core and opening design) aiming to examine the performance sensitivity of several proposed configurations in response to indoor environmental quality and ventilation performance of deep, open-plan, naturally ventilated office typologies.

It was predicted that reduced-scale water-bath modelling could be effectively used to validate the CFD models, as it provides significant detail of airflows using water at smaller scales. CFD results of the top floors showed reduced ventilation performance of a space served by both high-level inlets and outlets. However, higher ventilation rates (above $2.50 \mathrm{ACH})$ and cooler air temperatures $\left(2.74{ }^{\circ} \mathrm{C}\right)$ were predicted in the mid-level vertical 
opening cases. Also predicted was minimal thermal stratification with similar air velocities throughout, suggesting the creation of a potentially comfortable internal environment. However, these were often at higher temperatures in the high-level horizontal HLH cases.

Fresh air from mid-level vertical MLV assisted the removal of air at high level however, these increased vertical thermal differences by 33\%. Bi-directional flow was observed in some roof lanterns, regardless of façade opening design. Instances of flow recirculation and diversion were revealed in the shallow zone of the $\mathrm{O} 2 / \mathrm{O} 4$ cases. These outcomes can be used as guidelines in arranging the office layout, so that occupants could be positioned appropriately to minimise draught and discomfort.

Atria surrounded by buildings cores, led to higher velocities and temperatures throughout the occupied zone. Improved ventilation performance was predicted in cases where the cores are positioned on facades furthest away from an atrium with a shape that replicates that of the building.

The proposed designs investigated have been shown to deliver higher ventilation rates and cooler temperatures in comparison to their respective base levels of performance, the best performing opening design being $\mathrm{O} 2 / \mathrm{O} 4$ (MLV openings). Nevertheless, implementation of specific combinations of these parameters can define the optimal design in order to sufficiently condition a deep, open-plan office using natural ventilation; this being A3C2O2; a short-façade core configuration, complimented by mid-level vertical openings.

In conclusion, results obtained from the sensitivity analysis performed would advance knowledge of air flow characteristics and ventilation performance of the various opening designs when implemented in the archetypal building. The significance of these improvements could be perceived in the justification of complex naturally ventilation design decisions tasked with enhancing a space's IEQ.

\section{Acknowledgments}

The authors would like to thank Professor Malcolm Cook, Mr Roger Bennett, Mr Jonathan Hales and the Loughborough University laboratory technicians for their invaluable guidance and expertise which made this research possible. This research was funded by Loughborough University and Engineering and Physical Sciences Research Council (EPSRC), and was supported by Chris Trott of Foster + Partners. 


\section{References:}

Abdullah, H. and H, Z,. Alibaba (2020). Window Design of Naturally Ventilated Offices in the Mediterranean Climate in Terms of CO2 and Thermal Comfort Performance. Sustainability 2020, 12, 473, 1-33

Acred, A. and G. R. Hunt (2013). Multiple Flow Regimes in Stack Ventilation of Multi-Storey Atrium Buildings. Int. J. Vent. 12(1), 31-40.

Acred, A. and G. R. Hunt (2014). A simplified mathematical approach for modelling stack ventilation in multicompartment buildings. Build. Environ. 71, 121-130.

Acred, A. and G. R. Hunt (2015). Optimising a multi-storey atrium building for stack ventilation. CIBSE Tech. Symp. (February).

Aldawoud, A. (2016). Windows design for maximum cross-ventilation in buildings. Adv. Build. Energy Res. (April), 1-20.

Anand, Y., A. Gupta, S. Tyagi, and S. Anand (2016). Computational fluid dynamics, a building simulation tool for achieving sustainable buildings. Renew. Sustain. Energy Rev. 57, 1174-1185.

ANSI/ASHRAE Standard 62.1 (2013). The Standards For Ventilation and Indoor Air Quality.

ANSYS Inc. (2016). Computational Fluid Dynamics Software

BSI (2007). BS EN 15251 Indoor environmental input parameters for design and assessment of energy performance of buildings

Carrilho da Graca, G. and P. Linden (2016). Ten questions about natural ventilation of non-domestic buildings. Build. Environ. 107, 263-273.

Chalkias, A., H. Moran, N. Clark, and H. Moran (2014). Desk Power Load Monitoring. (June).

Chen, Q., K. Lee, S. Mazumdar, S. Poussou, L. Wang, M. Wang, and Z. Zhang (2010). Ventilation performance prediction for buildings: Model assessment. Build. Environ. 45(2), 295-303.

Chenari, B., J. Dias Carrilho, and M. Gameiro da Silva (2016). Towards sustainable, energy-efficient and healthy ventilation strategies in buildings: A review. Renew. Sustain. Energy Rev. 59, 14261447.Chenvidyakarn, T. (2013). Buoyancy Effects on Natural Ventilation (1 ed.). Cambridge University Press. 
Chenvidyakarn, T. and A. W. Woods (2010). On the natural ventilation of two independently heated spaces connected by a low-level opening. Build. Environ. 45(3), 586-595.

Chenvidyakarn, T. and A. Woods (2005). Multiple steady states in stack ventilation. Build. Environ. 40 (3).

CIBSE (2017). Designing a natural ventilation strategy for Bloomberg's central London HQ.

CIBSE AM10 (2014). CIBSE Applications Manual 10: Natural ventilation in non-domestic buildings.

Doheim R. M., Y.G. Yohanis, A. Nadjai, H. Elkadi (2013). The impact of atrium shape on natural smoke ventilation. Fire Safety Journal 63 (2014) 9-16.

Fisk, W. J. and A. H. Rosenfeld (1997). Estimates of improved productivity and health from better indoor environments. Indoor Air 7, 158-172.

Ga-Young Cho, Myoung-Souk Yeo and Kwang-Woo Kim (2013) Design Parameters of Double-Skin Façade for Improving the Performance of Natural Ventilation in High Rise Residential Buildings, Journal of Asian Architecture and Building Engineering, 12:1, 125-132,

Hussain, S. and P. H. Oosthuizen (2012). Numerical investigations of buoyancy-driven natural ventilation in a simple atrium building and its effect on the thermal comfort conditions. Appl. Therm. Eng. 40, 358-372.

Hussain, S. and P. H. Oosthuizen (2013). Numerical investigations of buoyancy-driven natural ventilation in a simple three-storey atrium building and thermal comfort evaluation. Appl. Therm. Eng. 57(1-2), 133-146.

ISO 7730 (2005). Ergonomics of the Thermal Environment - Analytical Determination and Interpretation of Thermal Comfort Using Calculation of the PMV and PPD Indices and Local Thermal Comfort Criteria.

Ji, Y., M. Cook, and V. Hanby (2007,). CFD modelling of natural displacement ventilation in an enclosure connected to an atrium. Build. Environ. 42(3), 1158-1172.

Kleiven, T. (2003). Natural Ventilation in Buildings -Architectural concepts, consequences and possibilities. Ph. D. thesis, Norwegian university of Science and Technology.

Korolija, I., L. Marjanovic-Halburd, Y. Zhang, and V. Hanby (2013, may). UK office buildings archetypal model as methodological approach in development of regression models for predicting building energy consumption from heating and cooling demands. Energy Build. 60, 152-162. 
Linden, P. F., G. F. Lane-Serff, and D. A. Smeed (1990). Emptying filling boxes: the fluid mechanics of natural ventilation. J. Fluid Mech. 212, 309-335.

Lomas, K. J. (2007). Architectural design of an advanced naturally ventilated building form. Energy Build. 39(2), 166-181.

Marmot, A. and J. Eley (2000). Office Space Planning: Designing for Tomorrow's Workplace. London, UK: McGraw-Hill.

Moosavi, L., N. Ghafar, and N. Mahyuddin (2016). Investigation of Thermal Performance for Atria: a Method Overview. MATEC Web Conf. 66, 00029.

Moosavi, L., N. Mahyuddin, N. Ab Ghafar, and M. Azzam Ismail (2014). Thermal performance of atria: An overview of natural ventilation effective designs. Renew. Sustain. Energy Rev. 34, 654-670.

Ravikumar, P. and D. Prakash (2009). Analysis of thermal comfort in an office room by varying the dimensions of the windows on adjacent walls using CFD: A case study based on numerical simulation. Build. Simul. 2(3), $187-196$.

Short, C. and S. Al-Maiyah (2009). Design strategy for low-energy ventilation and cooling of hospitals. Build. Res. Inf. 37(3), 264-292.

Spentzou, E., Cook, M and Emmitt, S. (2018). Natural ventilation strategies for indoor thermal comfort in Mediterranean apartments. Build Simul 11, 175-191. doi.org/10.1007/s12273-017-0380-1

Todd, S. (2016). Water bath modelling of transient and time dependent natural ventilation flows Water Bath Modelling of Transient and. Doctor of philosophy, Loughborough University.

Van Meel, J., Y. Martens, and H. Jan Van Ree (2010). Planning Office Spaces. London, UK: Laurence King Publishing, Ltd.

Wargocki, P., Z. Bako-Biro, G. Clausen, and P. O. Fanger (2002). Air quality in a simulated office environment as a result of reducing pollution source and increasing ventilation. Energy Build. 34, 775-783

WGBC (World Green Building Council) (2016). Green \& Healthy Work Spaces 
Wyon, D. P. (2004). The effects of indoor air quality on performance and productivity. Indoor Air 14 Suppl 7 (Suppl 7), 92-101.Yang, T., R. A. Buswell, and M. J. Cook (2011). Exploring rapid prototyping techniques for validating numerical models of naturally ventilated buildings. Proc. Build. Simul. 2011 12th Conf. Int. Build. Perform. Simul. Assoc., 965-971. 
Figures:

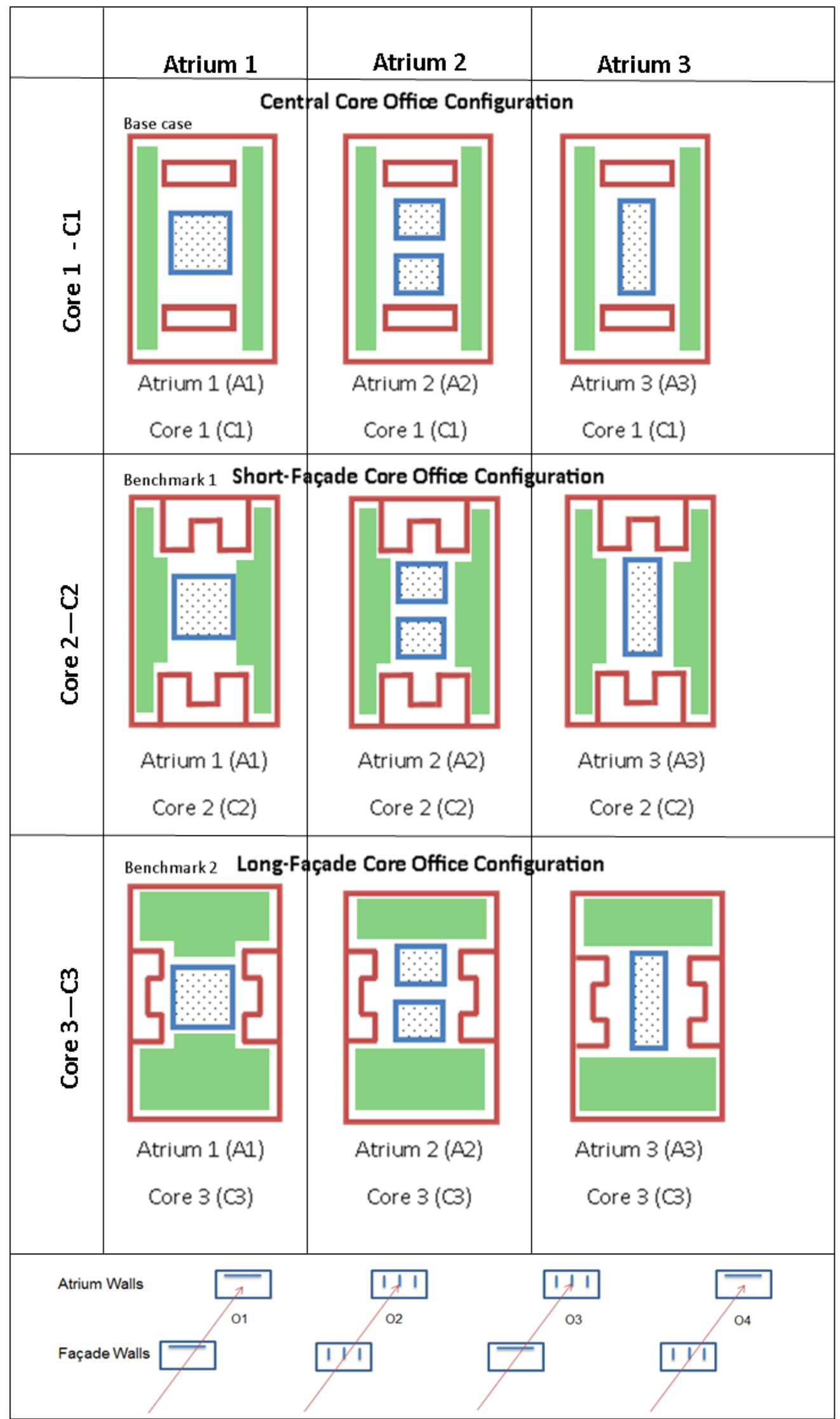

Figure 1 - Plan view of 36 model variants of office design and applied opening types to all atrium and core configurations. Green area $=$ Occupied zone. Blue $=$ atrium. Red $=$ Core . 


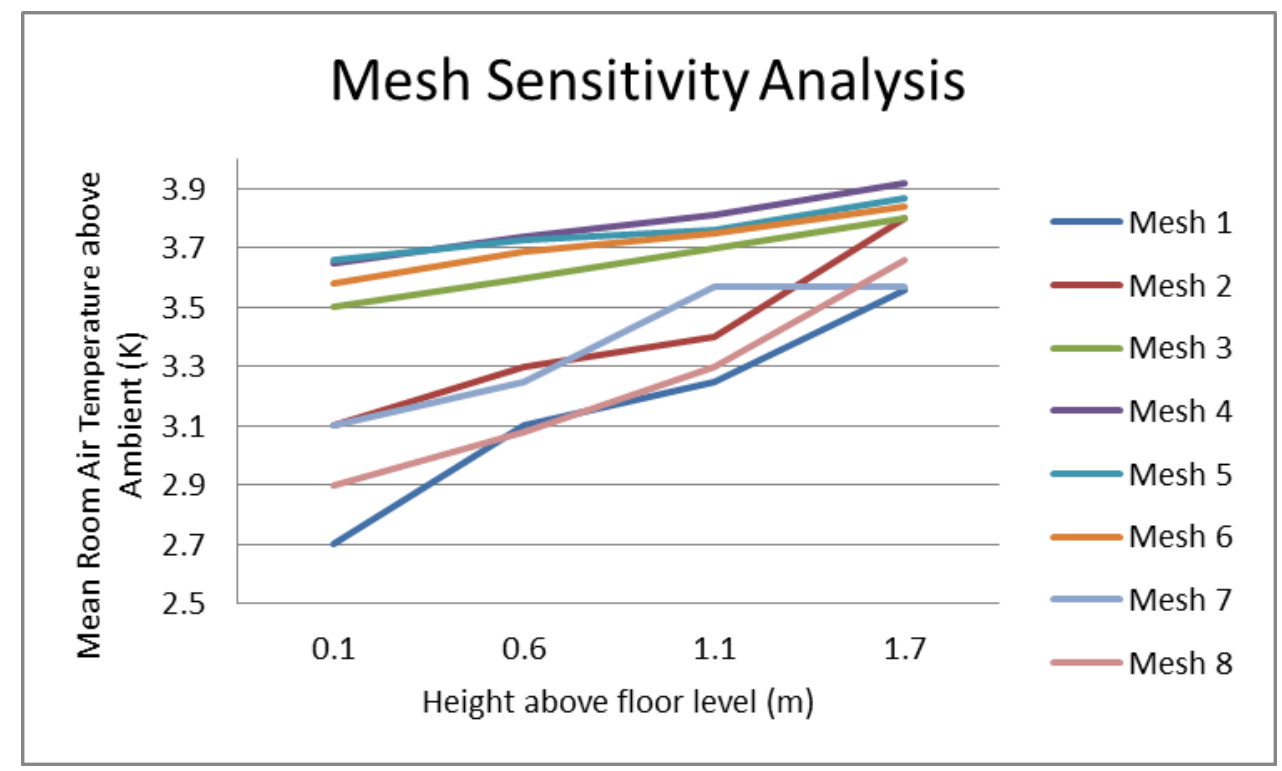

Figure 2 - Mesh Sensitivity study using mean room air temperature at various heights throughout the office.

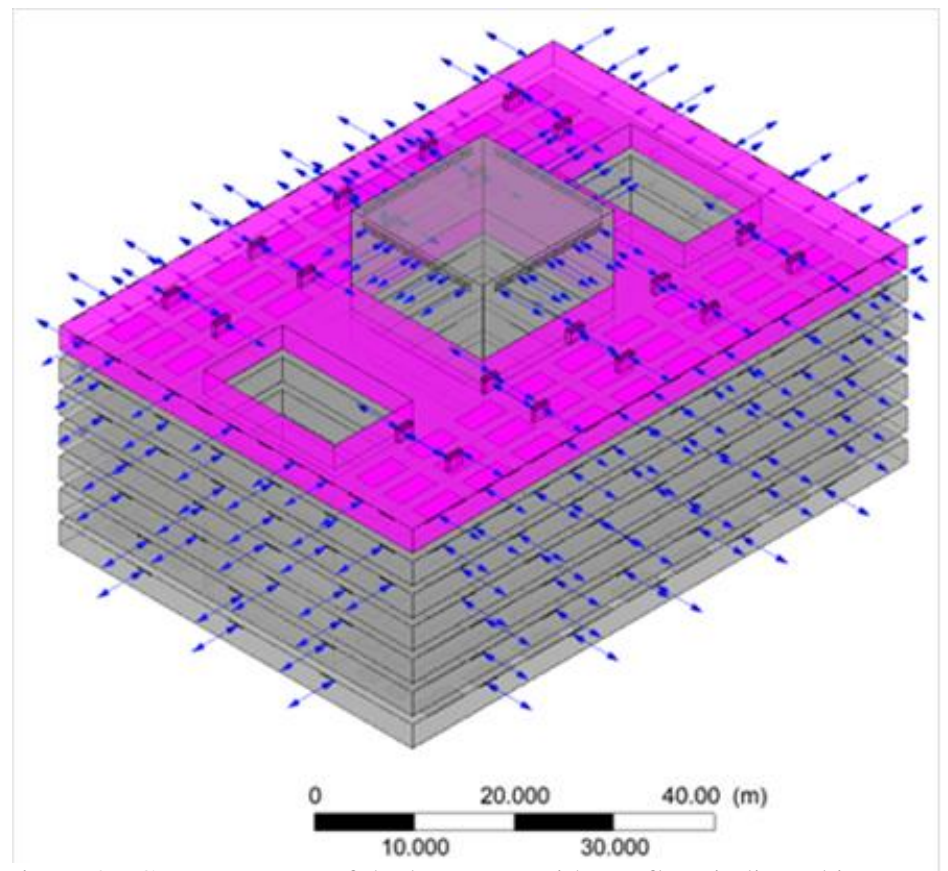

Figure 3 - CFD geometry of the base case with top floor indicated in purple. Blue arrows indicate openings 


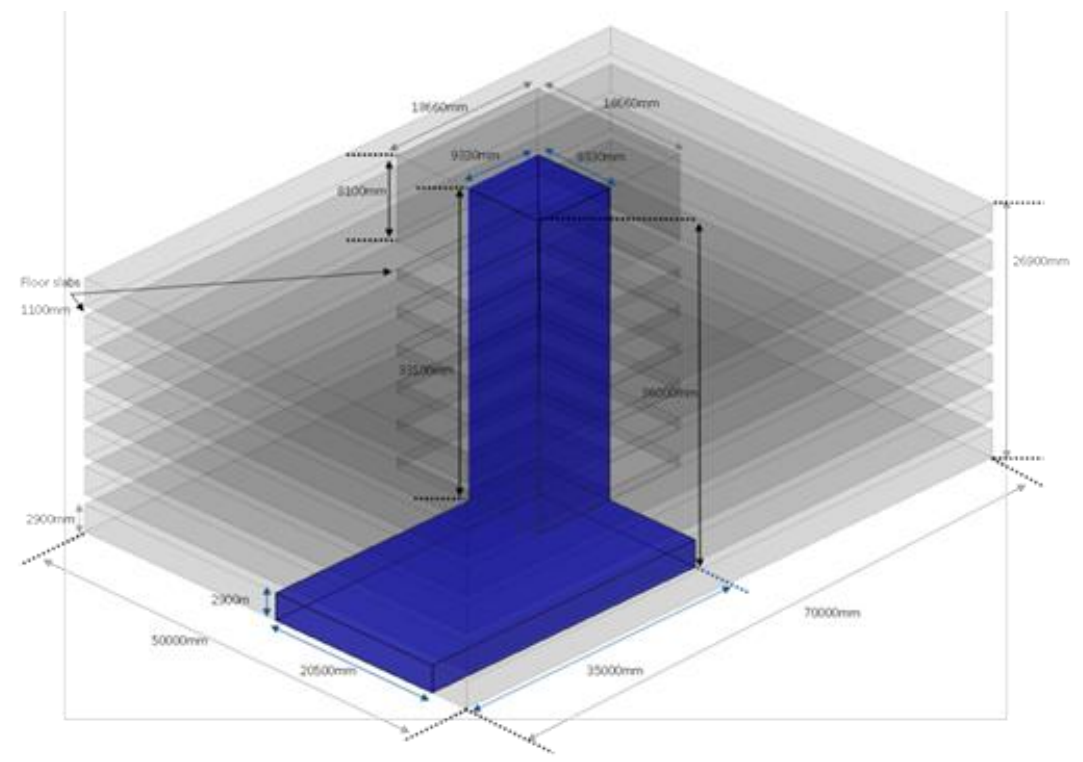

Figure 4 - Digital representation of the two CFD models. Full-Scale (grey) and WBM (blue)

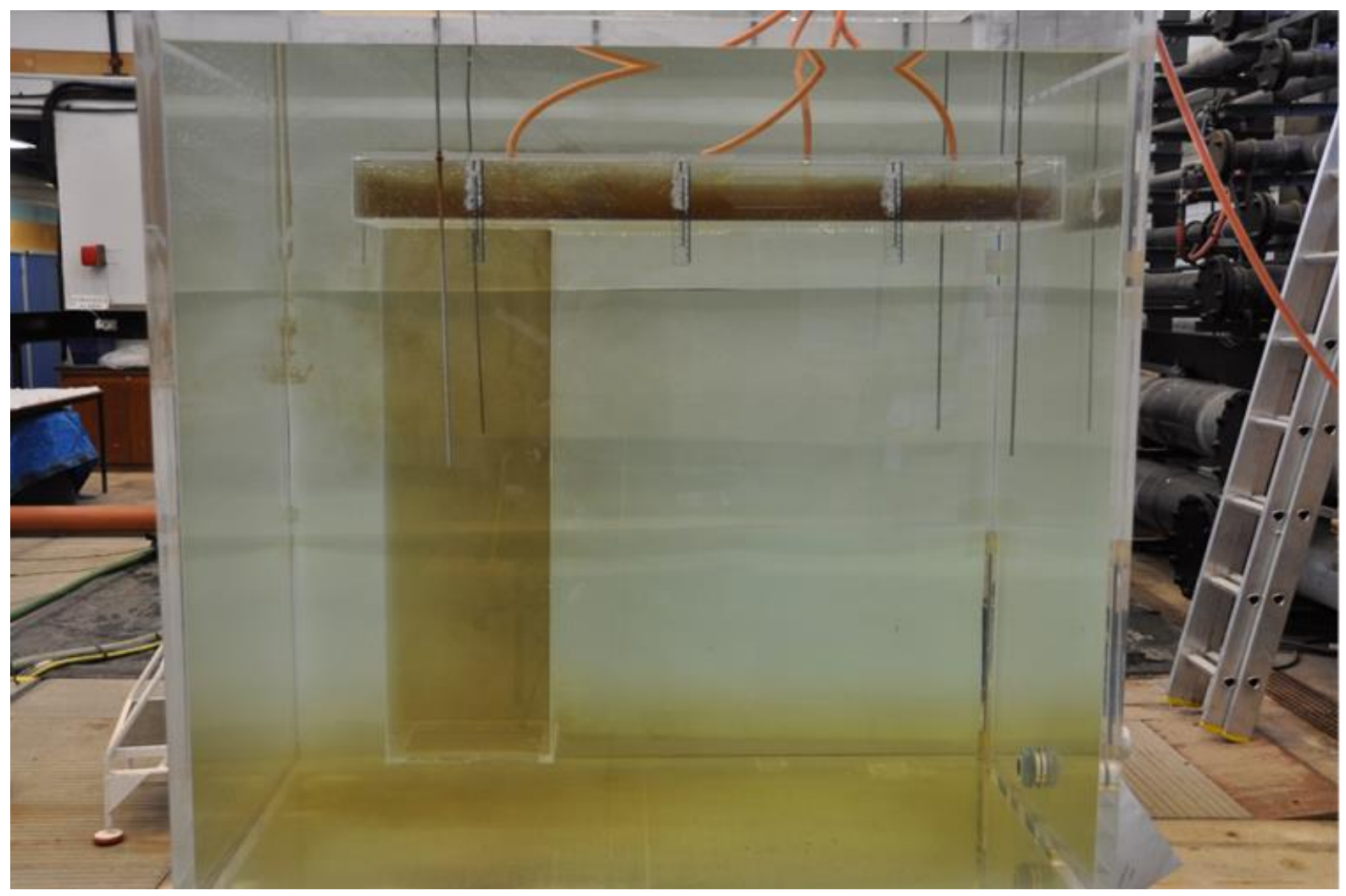

Figure 5 - WBM set-up of the base case simulation. 


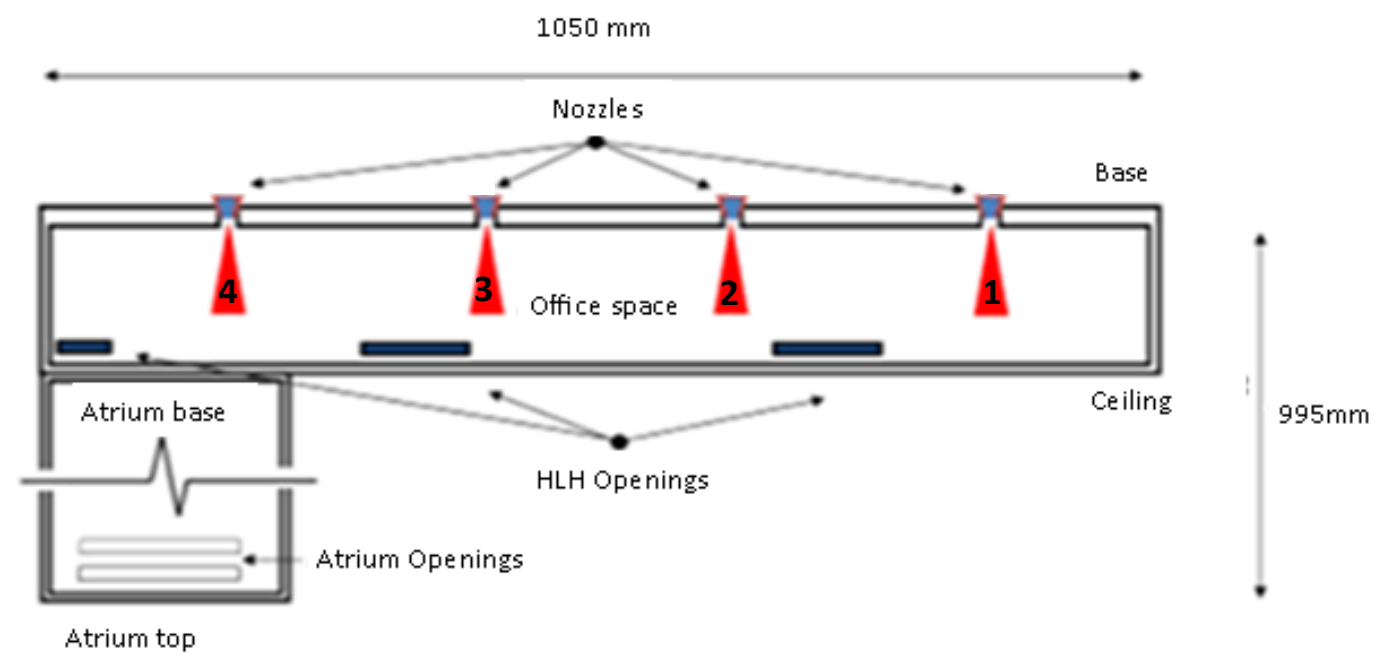

\begin{tabular}{|l|c|c|c|c|}
\hline & \multicolumn{4}{|c|}{ Nozzle Activity } \\
\hline Case & $\mathbf{4}$ & $\mathbf{3}$ & $\mathbf{2}$ & $\mathbf{1}$ \\
\hline Base Case A & Active & Active & Active & Active \\
\hline Case B & Inactive & Inactive & Inactive & Active \\
\hline Case C & Inactive & Inactive & Active & Inactive \\
\hline Case D & Inactive & Active & Inactive & Inactive \\
\hline Case E & Active & Inactive & Inactive & Inactive \\
\hline Case F & Inactive & Active & Active & Inactive \\
\hline
\end{tabular}

Figure 6 - Schematic (top) and table (bottom) demonstrating nozzle location and activation of the WBM cases.

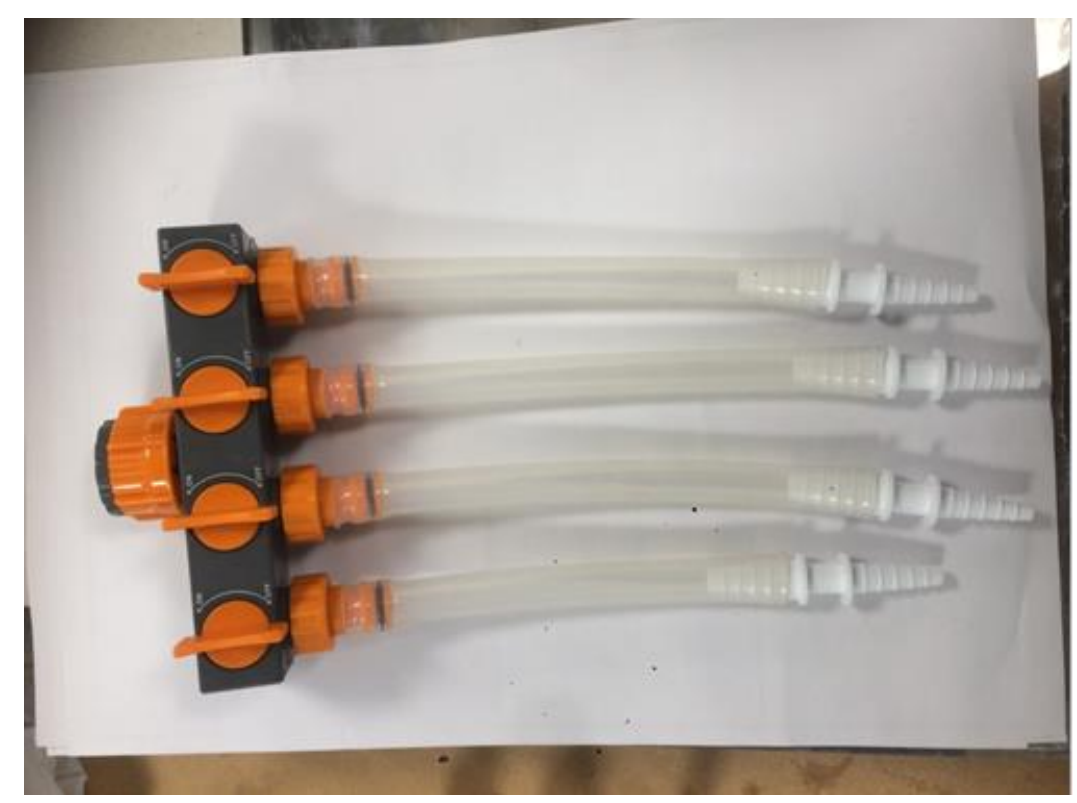

Figure 7 - Four way splitter used to supply to four nozzle with dyed salt solution. 


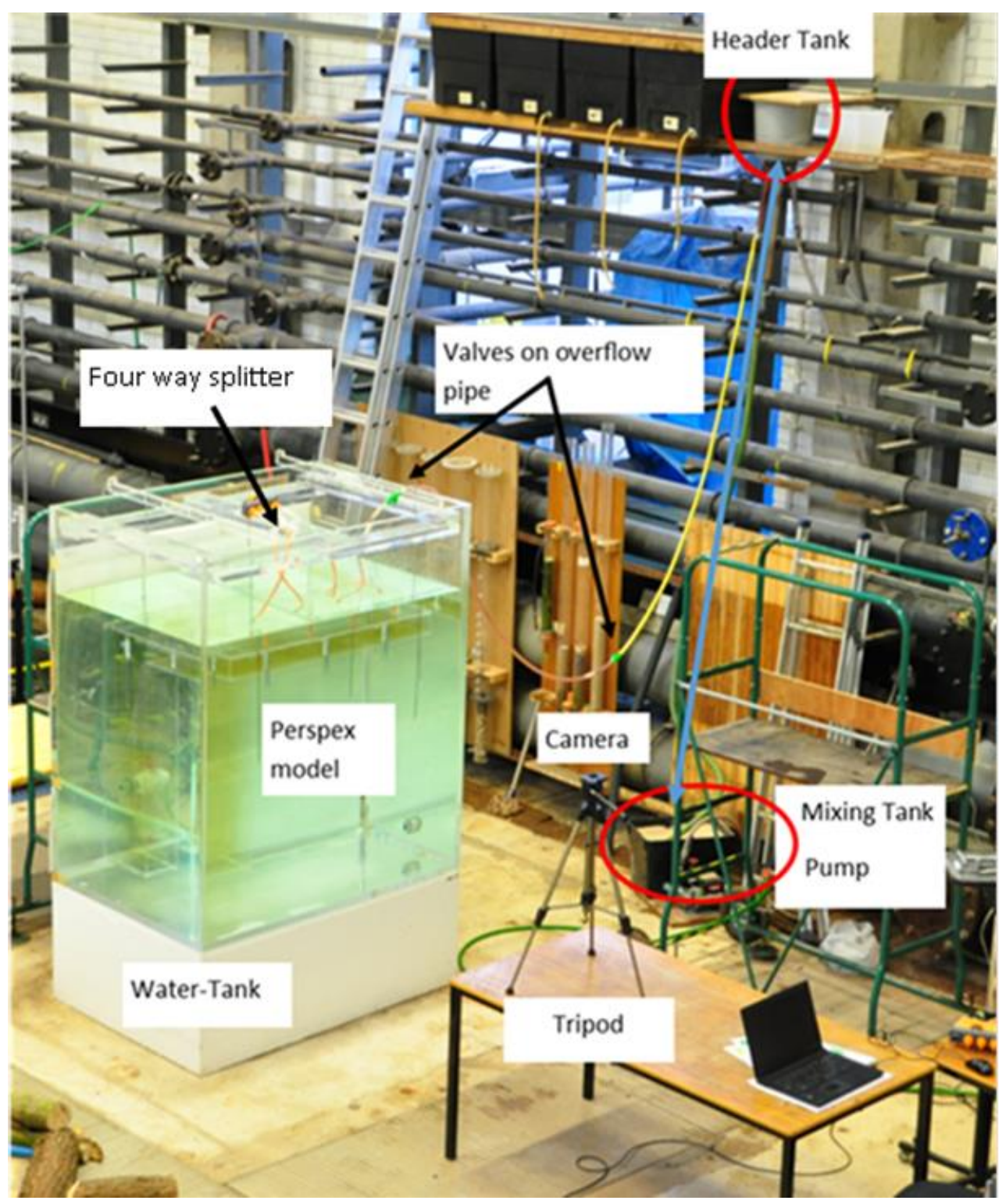

Figure 8 - Loughborough University's laboratory, WBM and Film set-up, WBM and Film set-up. Shown is the location of the mixing tank, header tank and overflow pipe connected to the four-way splitter. 


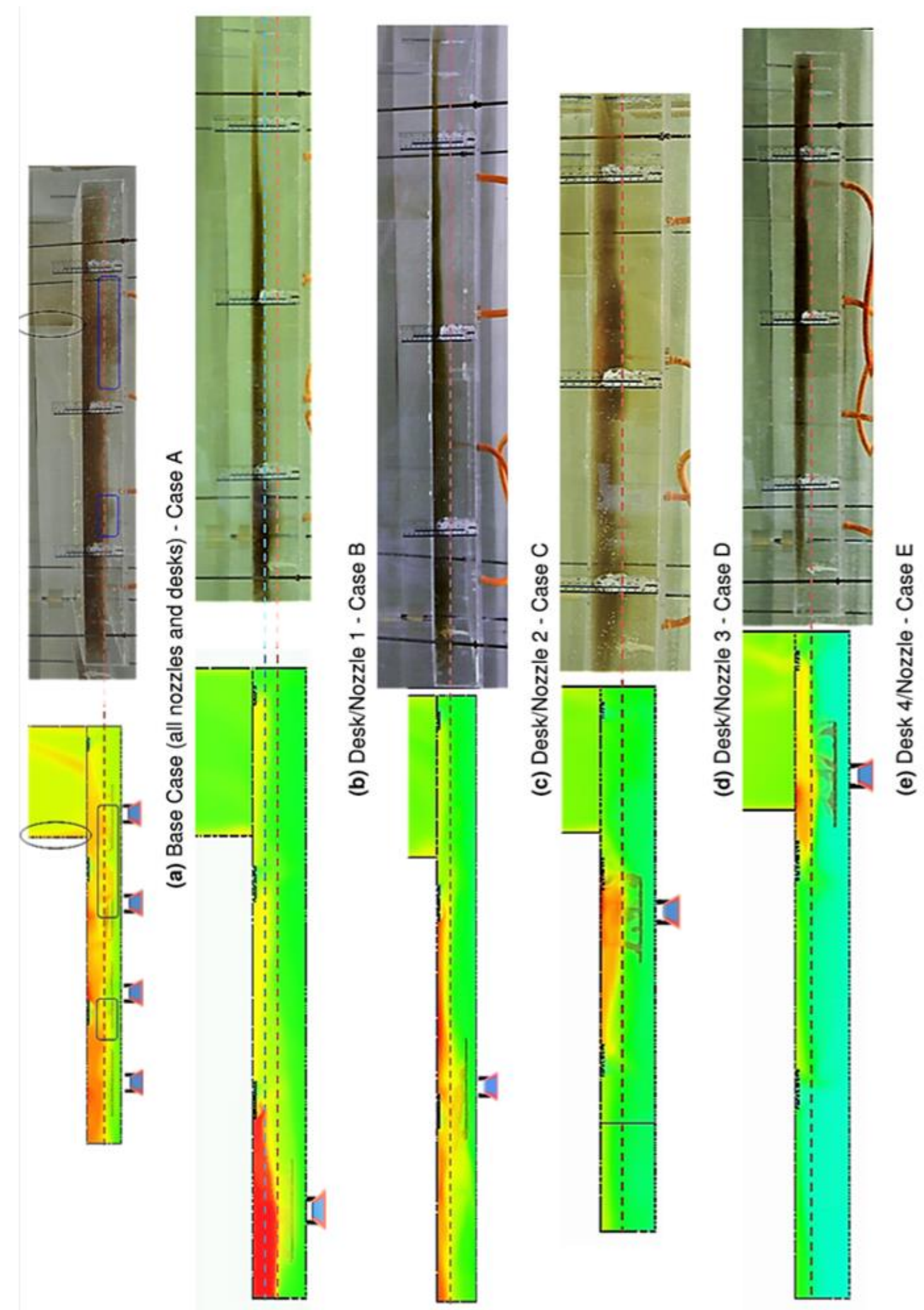

Figure 9 - WBM experiments and CFD simulations demonstrating predicted thermal distributions for the base case and several proposed cases, also highlighting the interface heights and flow characteristics. Dashed lines represent interface heights. 


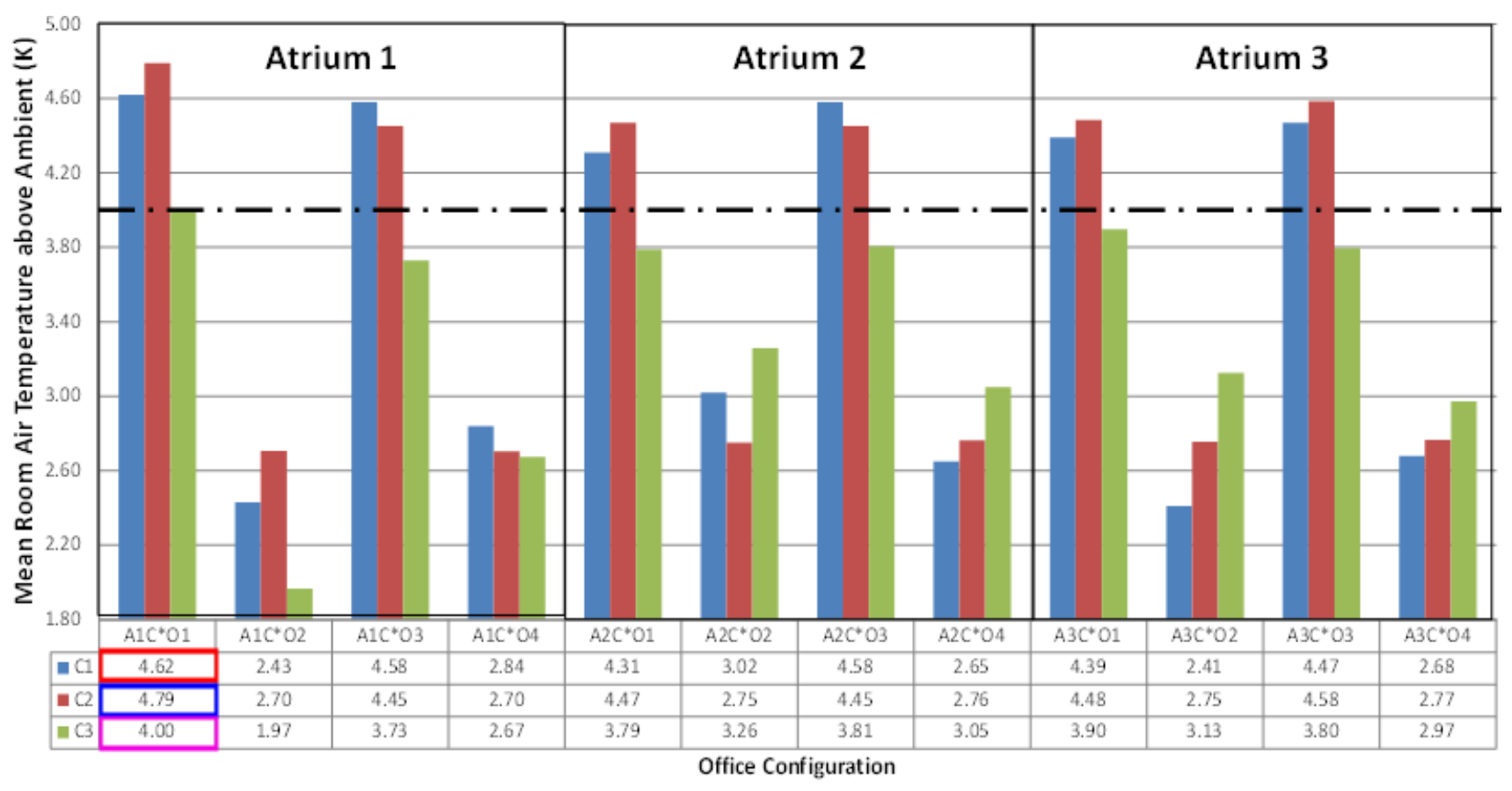

Figure 10 - Comparative design parameter analysis of predicted mean room air temperature above ambient. Black dashed line represents the $4.00 \mathrm{~K}$ overheating threshold

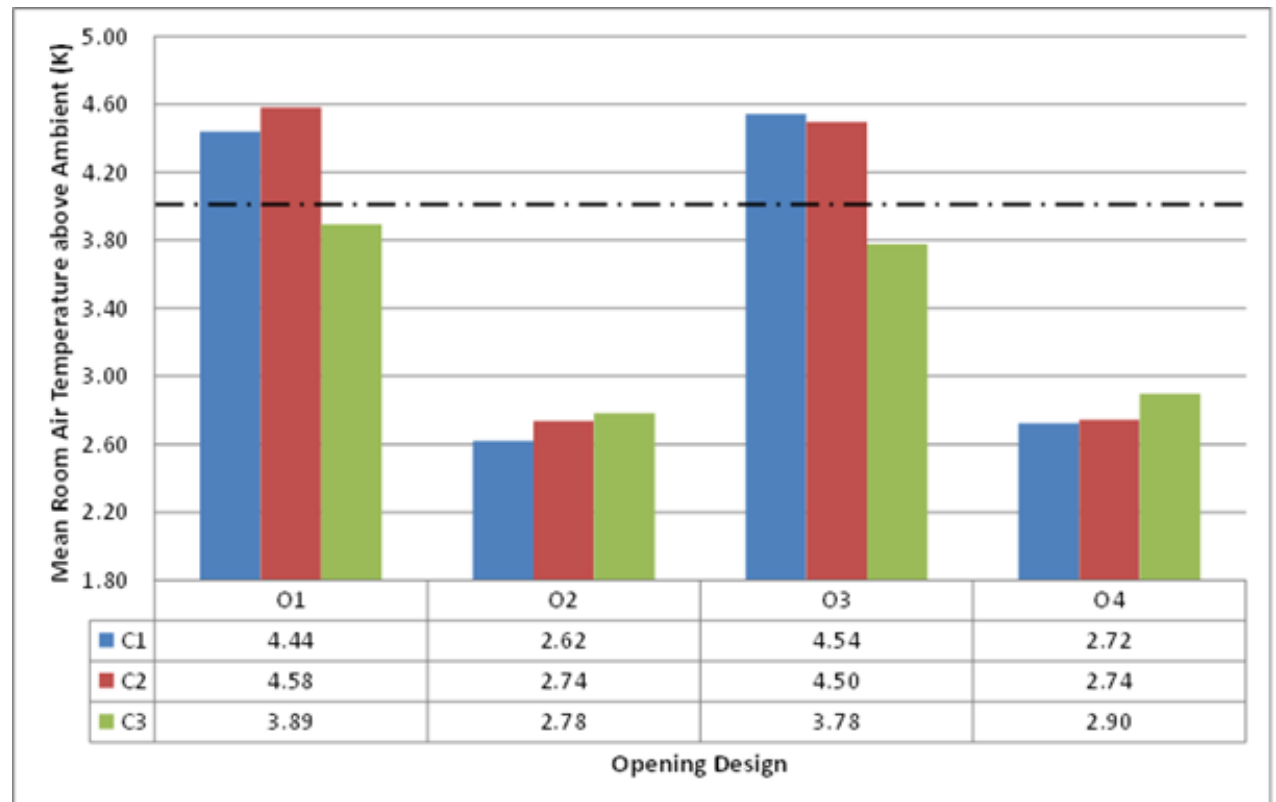

Figure 11 - Comparative design parameter analysis of predicted mean room air temperatures above ambient. Black dashed line represents the $4.00 \mathrm{~K}$ overheating threshold. 
A1C101

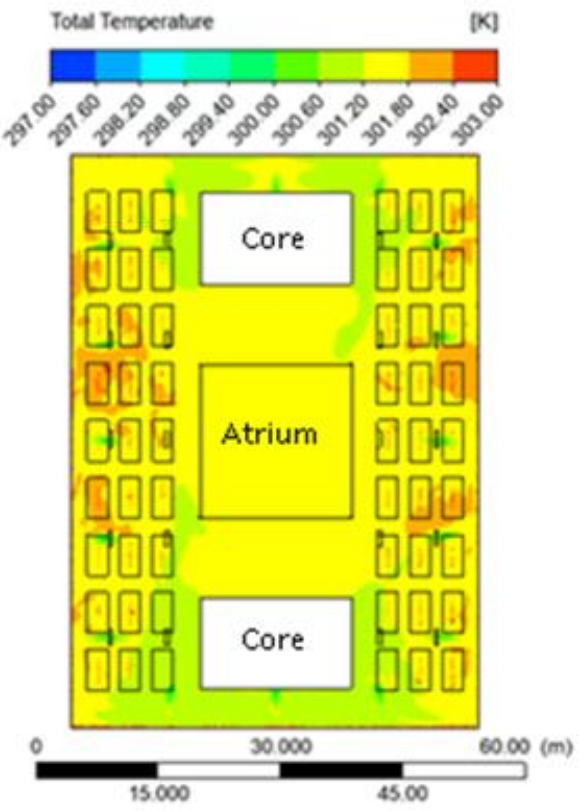

A1C102

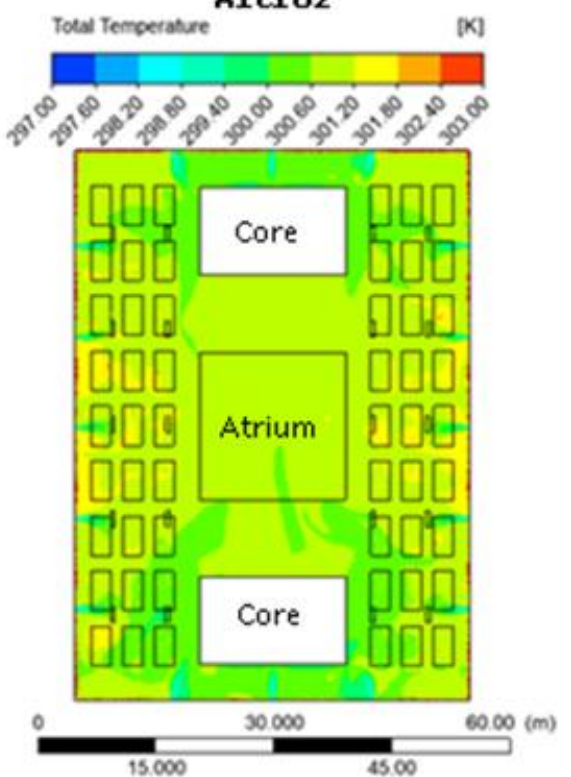

A2C101

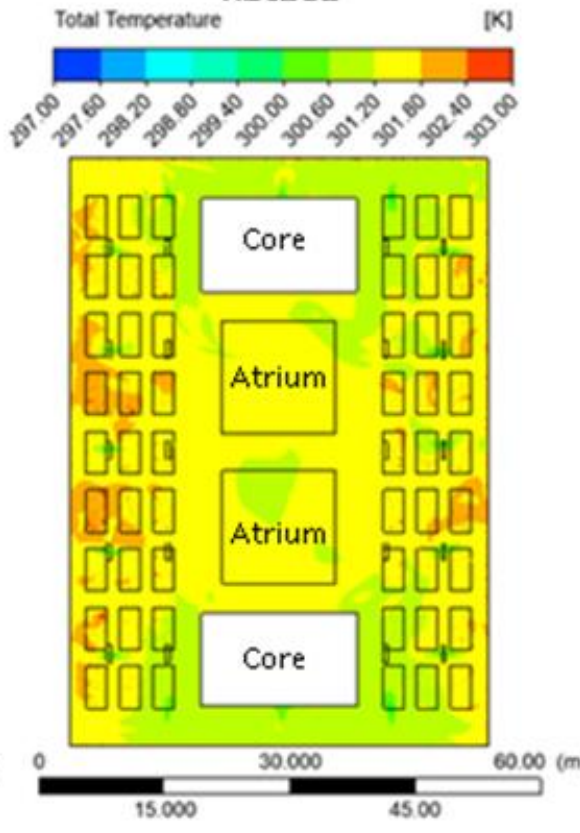

A2C102

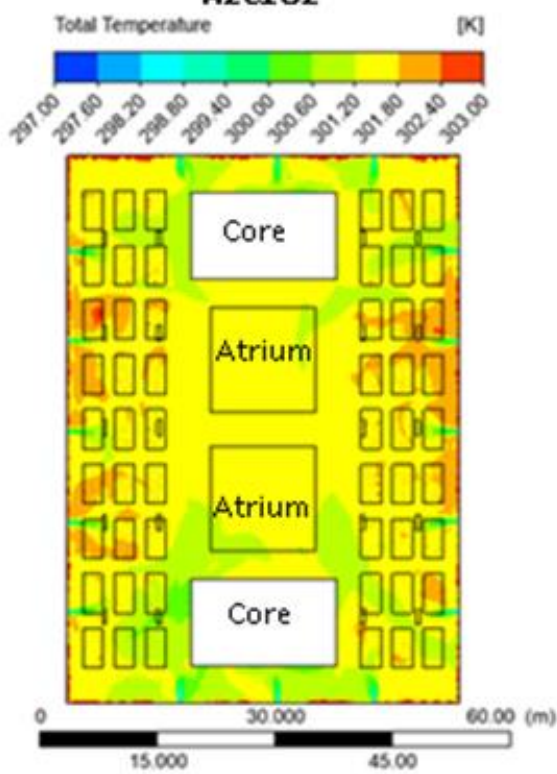

A3C101

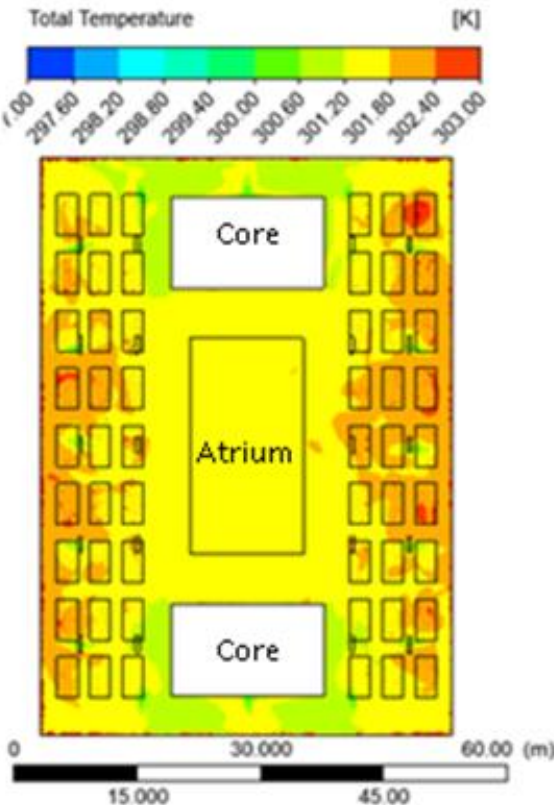

A3C102

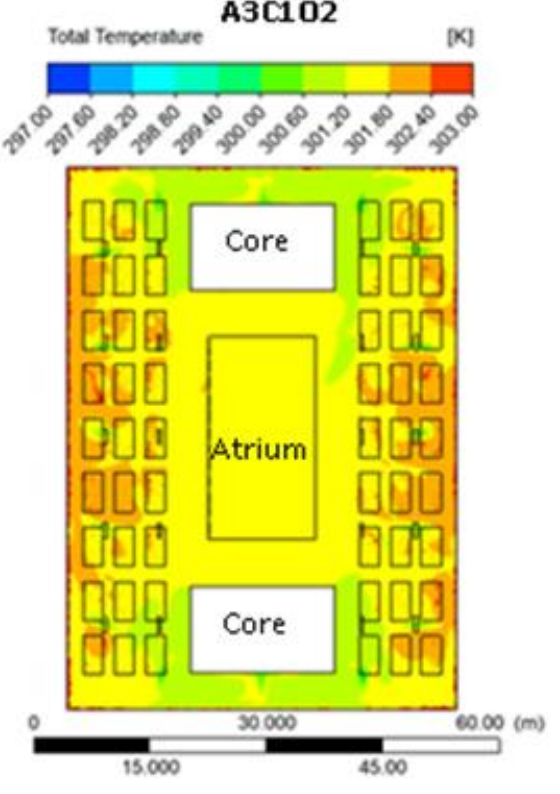

Figure 12 - Horizontal air temperature distribution, throughout the occupied zone, for Core 1 example cases. Desks (heat sources) represented by small rectangles either side of core and atria. 


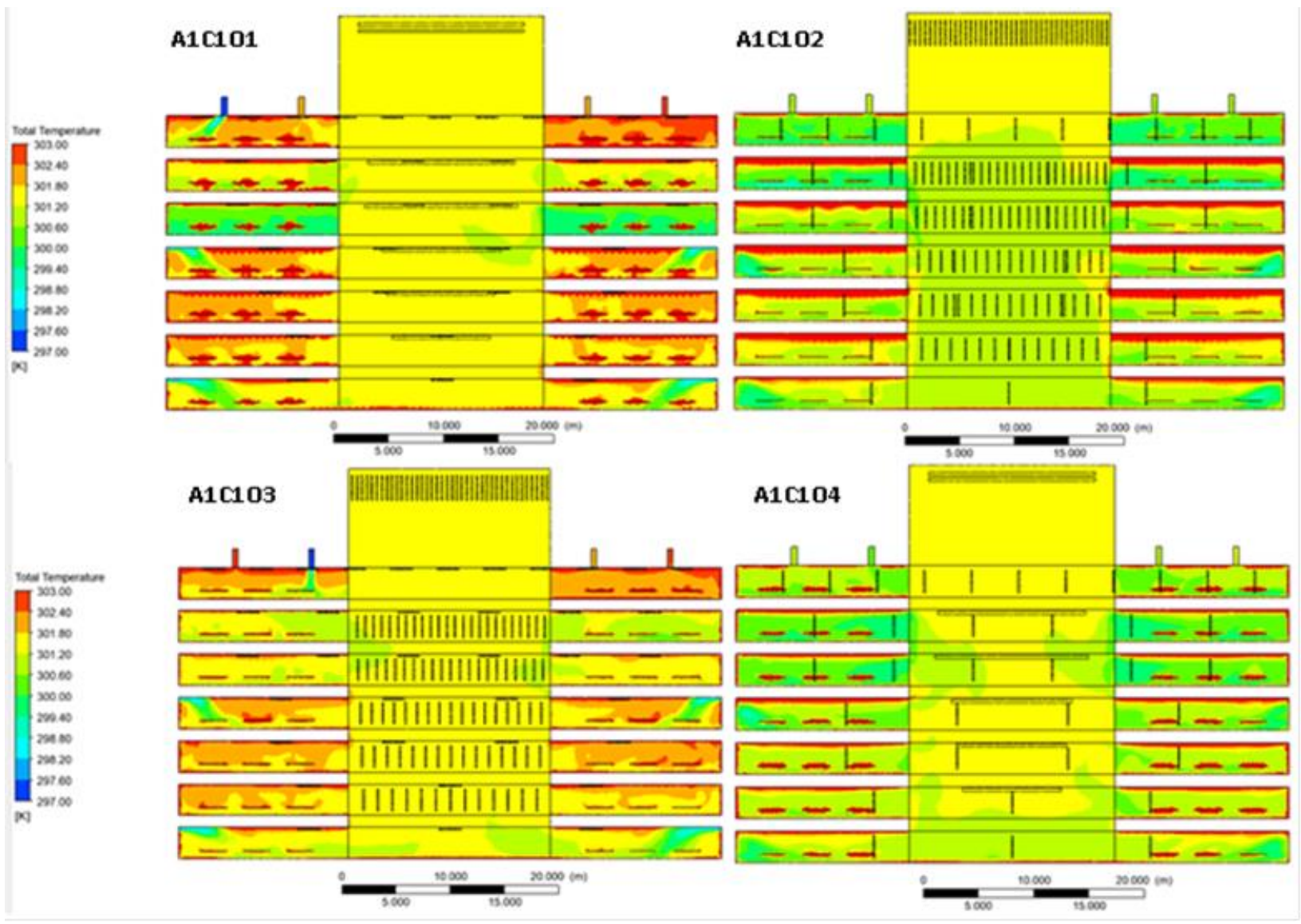

Figure 13 - Effect of opening design on vertical temperature distribution throughout Atrium 1 and Core 1 cases. 


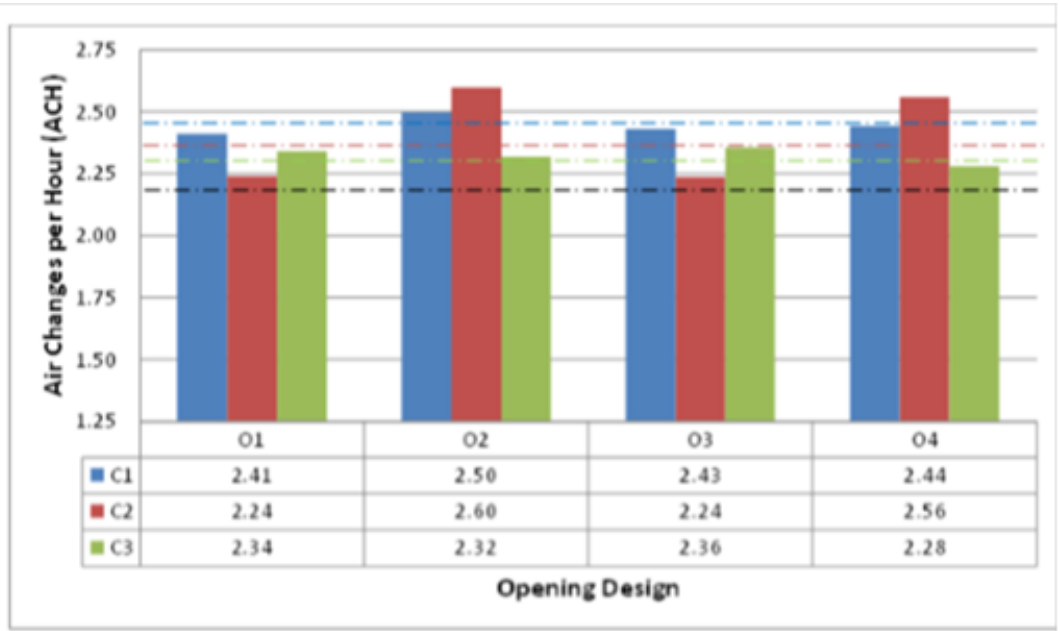

(a) Opening design

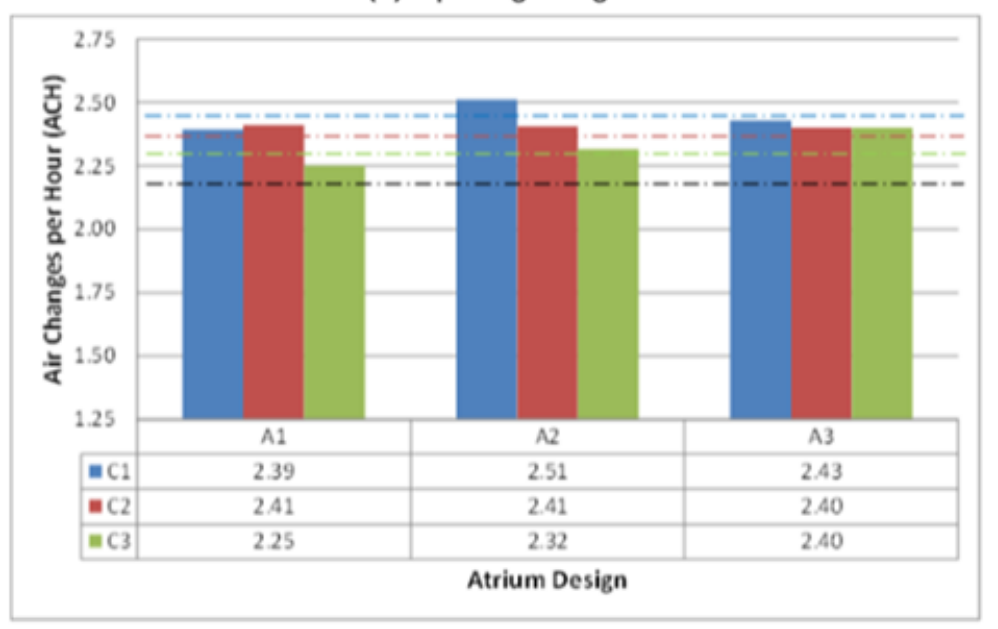

(b) Atrium design

Figure 14 - Effect of a design parameter change on ventilation performance. Dashed lines show design parameter averages (Blue C1, Red C2, Green C3) and Black shows the target ACH (2.2).

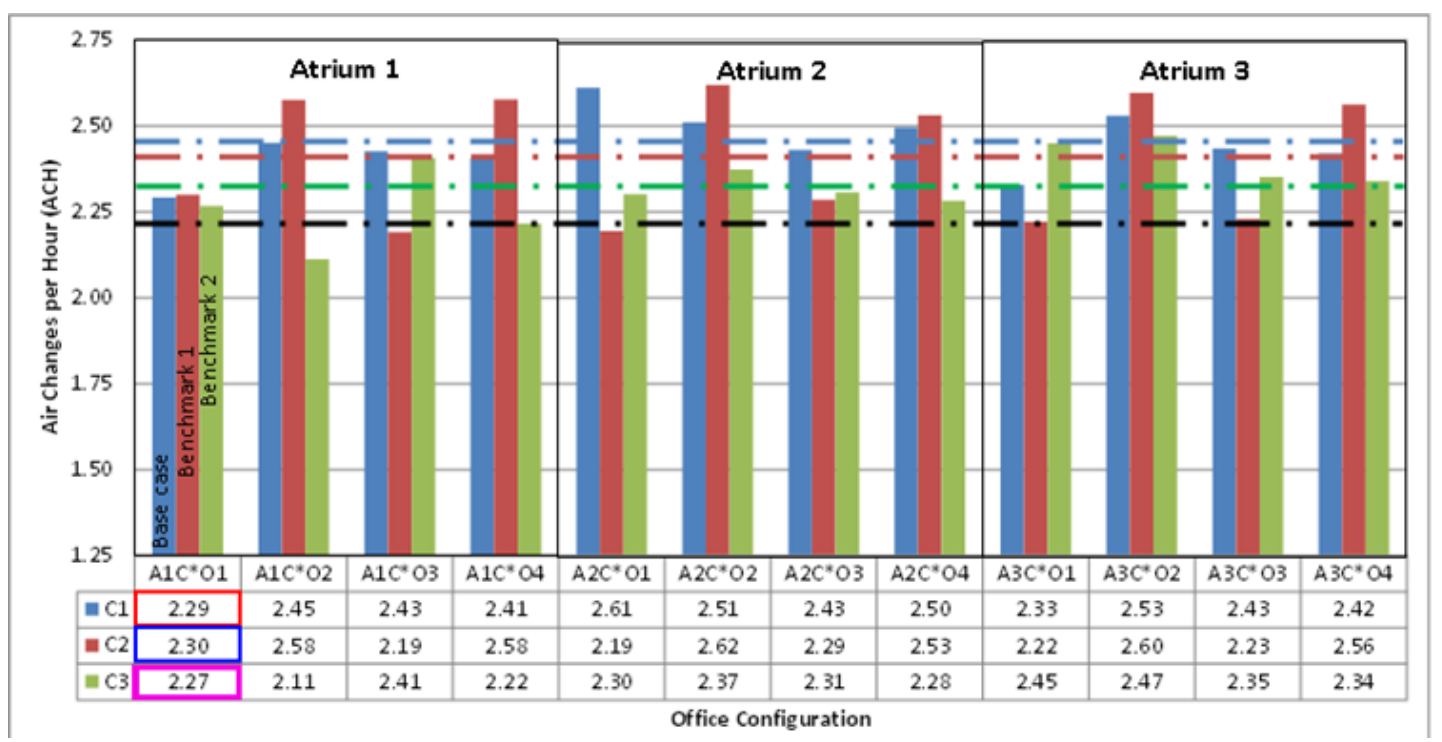

Figure 15 - Comparative core analysis of predicted ventilation rates. Dashed lines show design parameter averages (Blue C1, Red C2, Green C3) and Black shows the target ACH (2.2). 


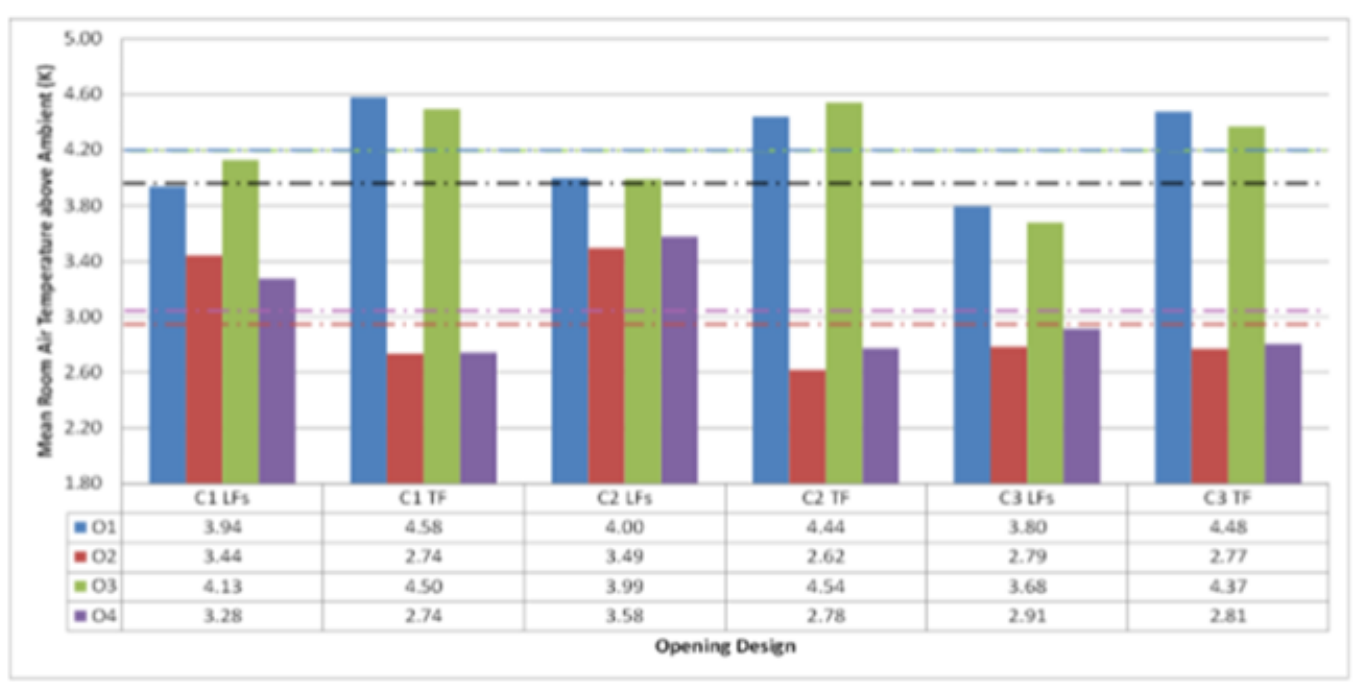

(a) Mean room air temperature above ambient

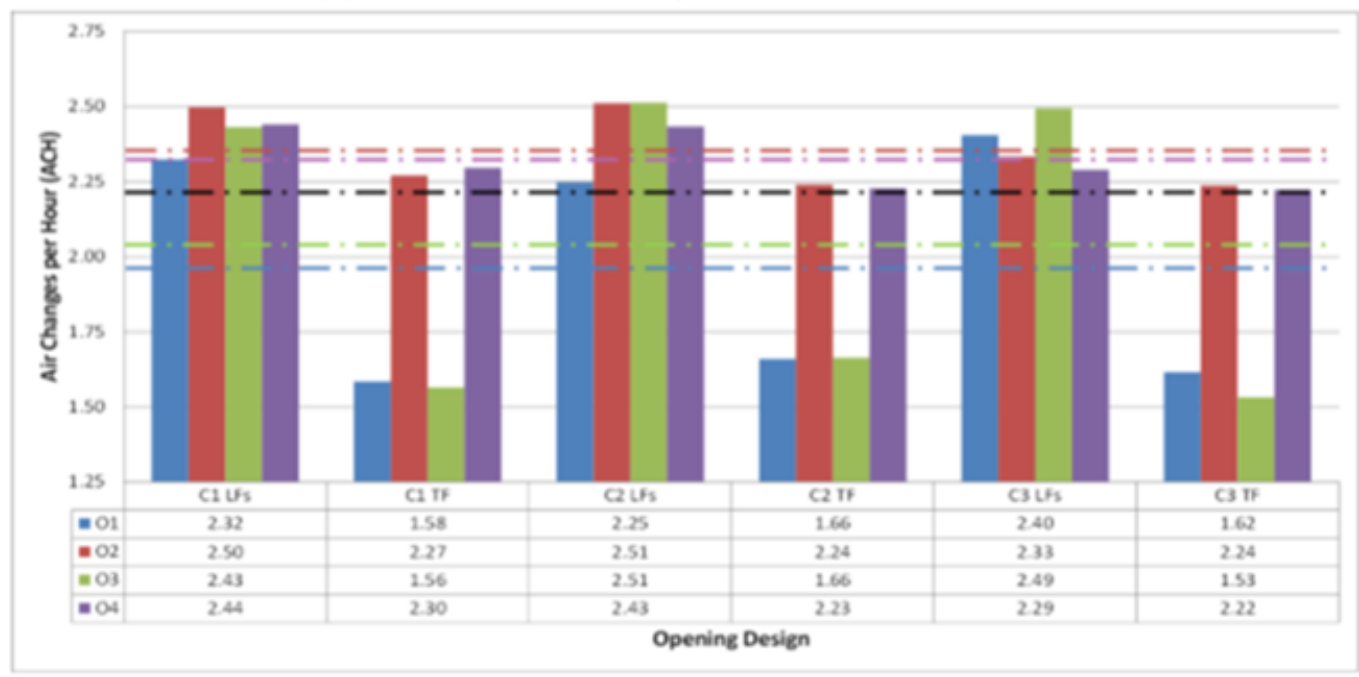

(b) Ventilation rates

Figure 16 - Predicted effect of opening design and exhaust method on ventilation performance. LF =Lower floors. $\mathrm{TF}=$ Top floor. Dashed lines show design parameter averages (Blue O1, Red O2, Green O3, Purple O4). In Figure 16a, black line shows the overheating threshold (4.00K). In Figure 16b, black line shows the target $\mathrm{ACH}(2.2 \mathrm{ACH})$. 


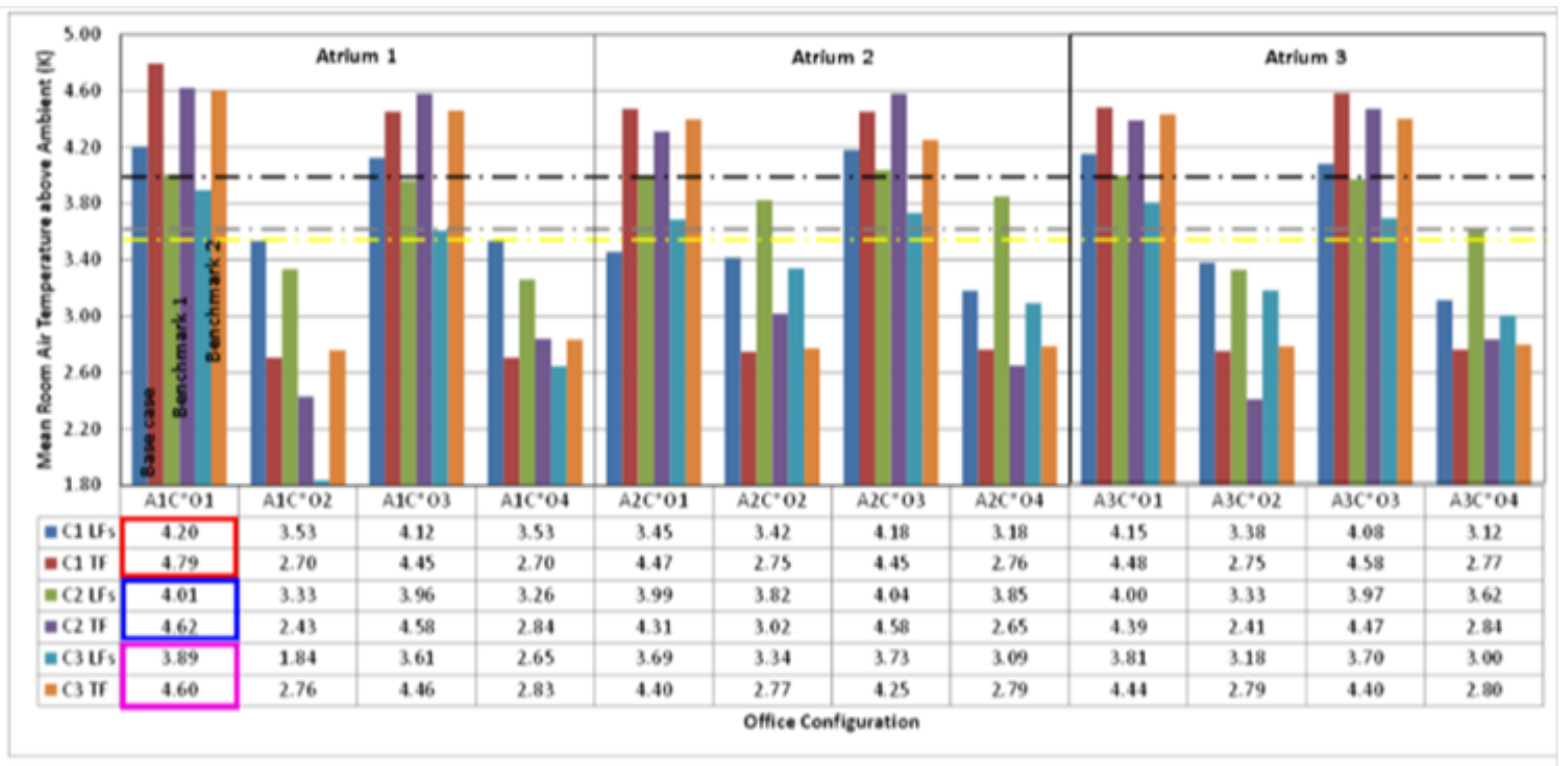

(a) Mean room air temperature

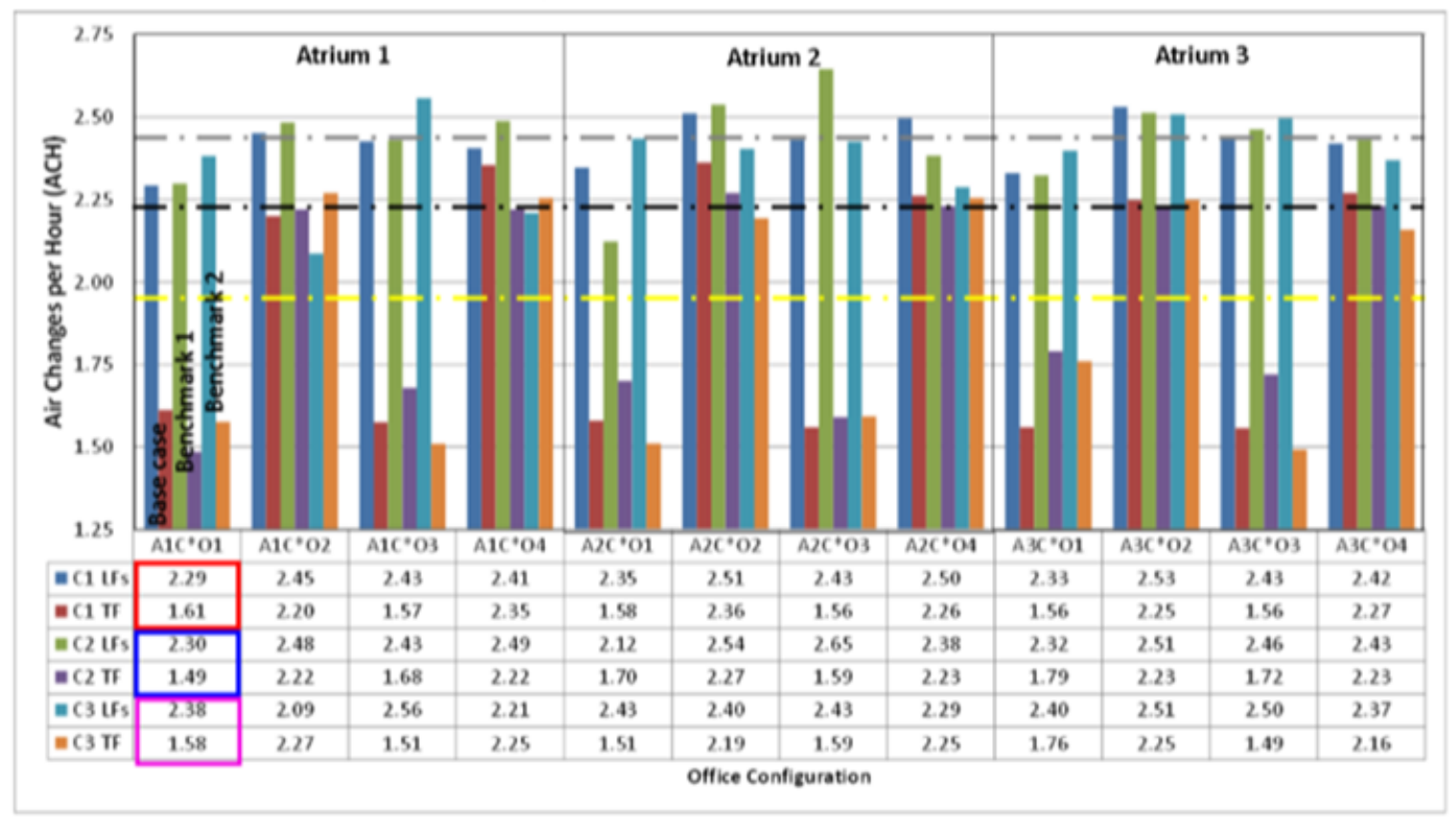

(b) Ventilation rates

Figure 17 - Comparative analysis of the predicted ventilation performance of exhaust methods. LF $=$ Lower floors. TF $=$ Top floor. Dashed lines show design parameter averages (Blue O1, Red O2, Green O3, Purple O4) In Figure 17a, black line shows the overheating threshold $(4.00 \mathrm{~K})$. In Figure 17b, black line shows the target ACH (2.2 ACH). 
Table 3 - Summary of the main findings.

\begin{tabular}{|c|c|c|c|c|c|c|c|c|c|c|c|c|c|c|c|}
\hline \multirow{3}{*}{\multicolumn{2}{|c|}{$\begin{array}{c}\text { Design } \\
\text { Parameter }\end{array}$}} & \multicolumn{3}{|c|}{ Average $\mathrm{ACH}(-)$} & \multicolumn{11}{|c|}{ Room Air Temperature above Ambient for various office locations (K) } \\
\hline & & \multirow[t]{2}{*}{ Mean } & \multirow{2}{*}{$\begin{array}{l}\text { Lower } \\
\text { Floors }\end{array}$} & \multirow{2}{*}{$\begin{array}{l}\text { Upper } \\
\text { Floors }\end{array}$} & \multirow[t]{2}{*}{ Mean } & \multicolumn{4}{|c|}{$\begin{array}{c}\text { Various heights of } \\
\text { interest above floor } \\
\text { level }(\mathrm{m})\end{array}$} & \multirow{2}{*}{$\begin{array}{c}\text { Average } \\
\text { Vertical } \\
\text { Stratification }\end{array}$} & \multicolumn{4}{|c|}{$\begin{array}{l}\text { Various office depths; shallow } 0-5 \mathrm{~m} \text {, } \\
\text { medium-deep } 5-10 \mathrm{~m} \text {, deep } 10-15 \mathrm{~m} \text { and } \\
\text { very-deep }>15 \mathrm{~m}\end{array}$} & \multirow{2}{*}{$\begin{array}{l}\text { Average } \\
\text { Horizontal } \\
\text { Stratification }\end{array}$} \\
\hline & & & & & & 0.1 & 0.6 & 1.1 & 1.7 & & Shallow & $\begin{array}{c}\text { Medium } \\
\text { deep }\end{array}$ & Deep & $\begin{array}{l}\text { Very } \\
\text { deep }\end{array}$ & \\
\hline \multirow{3}{*}{ 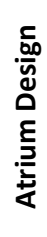 } & A1 & 2.14 & 2.38 & 2.02 & 3.57 & 3.45 & 3.56 & 3.63 & 3.78 & 0.33 & 3.45 & 3.56 & 3.63 & 3.78 & 0.33 \\
\hline & $\mathbf{A 2}$ & 2.17 & 2.42 & 1.82 & 3.62 & 3.54 & 3.63 & 3.73 & 3.81 & 0.29 & 3.54 & 3.63 & 3.73 & 3.81 & 0.29 \\
\hline & A3 & 2.19 & 2.43 & 2.04 & 3.60 & 3.53 & 3.63 & 3.72 & 3.79 & 0.24 & 3.53 & 3.63 & 3.72 & 3.79 & 0.24 \\
\hline \multirow{3}{*}{ 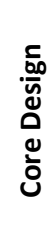 } & C1 & 2.18 & 2.38 & 1.91 & 3.67 & 3.66 & 3.79 & 3.83 & 3.99 & 0.33 & 3.66 & 3.79 & 3.83 & 3.99 & 0.28 \\
\hline & $\mathrm{C2}$ & 2.19 & 2.42 & 1.93 & 3.68 & 3.52 & 3.62 & 3.74 & 3.81 & 0.27 & 3.52 & 3.62 & 3.74 & 3.81 & 0.28 \\
\hline & C3 & 2.14 & 2.43 & 1.94 & 3.45 & 3.34 & 3.41 & 3.51 & 3.58 & 0.26 & 3.34 & 3.41 & 3.51 & 3.58 & 0.33 \\
\hline \multirow{4}{*}{ 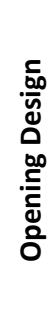 } & 01 & 1.97 & 2.32 & 1.58 & 4.20 & 3.96 & 4.10 & 4.14 & 4.24 & 0.28 & 3.96 & 4.10 & 4.14 & 4.24 & 0.26 \\
\hline & 02 & 2.35 & 2.45 & 2.25 & 2.98 & 3.05 & 3.14 & 3.23 & 3.33 & 0.28 & 3.05 & 3.14 & 3.23 & 3.33 & 0.33 \\
\hline & 03 & 2.03 & 2.48 & 1.59 & 4.20 & 3.97 & 4.08 & 4.21 & 4.31 & 0.33 & 3.97 & 4.08 & 4.21 & 4.31 & 0.27 \\
\hline & 04 & 2.32 & 2.39 & 2.25 & 3.02 & 3.04 & 3.10 & 3.19 & 3.30 & 0.26 & 3.04 & 3.10 & 3.19 & 3.30 & 0.26 \\
\hline
\end{tabular}

